\title{
Neuromonitoring with pulse-train stimulation for implantation of thoracic pedicle screws: a blinded and randomized clinical study. Part 1. Methods and alarm criteria
}

\author{
Clinical article
}

\author{
Blair Calancie, Ph.D., ${ }^{1}$ Miriam L. Donohue, Ph.D., ${ }^{2}$ Colin B. Harris, M.D.,${ }^{3}$ \\ Gregory W. Canute, M.D. ${ }^{4}$ Amit Singla, M.D., ${ }^{1}$ Kaitlin G. Wilcoxen, B.Sc., ${ }^{1}$ \\ AND Ross R. MoQuin, M.D. ${ }^{4}$
}

Departments of ${ }^{1}$ Neurosurgery and ${ }^{2}$ Cell and Developmental Biology, SUNY Upstate Medical University; ${ }^{3}$ Syracuse Orthopedic Specialists; and ${ }^{4}$ Crouse Neurosciences, Syracuse, New York

\begin{abstract}
Object. Reports of the accuracy of existing neuromonitoring methods for detecting or preventing medial malpositioning of thoracic pedicle screws have varied widely in their claimed effectiveness. The object of this study was to develop, test, and validate a novel neuromonitoring method for preventing medial malpositioning of pedicle screws in the thoracic spine during surgery.

Methods. This is a prospective, blinded and randomized study using a novel combination of input (4-pulse stimulus trains delivered within the pedicle track) and output (evoked electromyography from leg muscles) to detect pedicle track trajectories that-once implanted with a screw - would cause that screw to breach the pedicle's medial wall and encroach upon the spinal canal. For comparison, the authors also used screw stimulation as an input and evoked electromyogram from intercostal and abdominal muscles as output measures. Intraoperative electrophysiological findings were compared with postoperative CT scans by multiple reviewers blinded to patient identity or intraoperative findings.

Results. Data were collected from 71 patients, in whom 802 screws were implanted between the T-1 and L-1 vertebral levels. A total of 32 screws ended up with screw threads encroaching on the spinal canal by at least $2 \mathrm{~mm}$. Pulse-train stimulation within the pedicle track using a ball-tipped probe and electromyography from lower limb muscles correctly predicted all $32(100 \%)$ of these medially malpositioned screws. The combination of pedicle track stimulation and electromyogram response from leg muscles proved to be far more effective in predicting these medially malpositioned screws than was direct screw stimulation and any of the target muscles (intercostal, abdominal, or lower limb muscles) we monitored. Based on receiver operating characteristic analysis, the combination of 10-mA (lower alarm) and 15-mA stimulation intensities proved most effective for detection of pedicle tracks that ultimately gave rise to medially malpositioned screws. Additional results pertaining to the impact of feedback of these test results on surgical decision making are provided in the companion report.

Conclusions. This novel neuromonitoring approach accurately predicts medially malpositioned thoracic screws. The approach could be readily implemented within any surgical program that is already using contemporary neuromonitoring methods that include transcranial stimulation for monitoring motor evoked potentials.

(http://thejns.org/doi/abs/10.3171/2014.2.SPINE13648)
\end{abstract}

KEY WoRDS $\quad$ intraoperative neuromonitoring $\bullet \quad$ bone screws $\bullet \quad$ spine
thoracic vertebrae $\quad \bullet \quad$ thoracic surgical procedures

$\mathrm{P}$ OSTERIOR transpedicular spinal instrumentation and fusion is used to treat a variety of disorders of the thoracic spine, ${ }^{13,28,44,66}$ following on from the origi-

\footnotetext{
Abbreviations used in this paper: $\mathrm{AbH}=$ abductor hallucis; $\mathrm{Abs}$ $=$ abdominal muscles; $\mathrm{AUC}=$ area under the curve; $\mathrm{EMG}=$ electromyogram; IC = intercostal muscles; MAC = minimum alveolar concentration; $\mathrm{MEP}=$ motor evoked potential; Quads $=($ for purposes of this paper) rectus femoris and vastus lateralis; $\mathrm{ROC}=$ receiver operating characteristic; SSEP = somatosensory evoked potential; $\mathrm{TA}=$ tibialis anterior.
}

nal application of this fixation approach in the lumbosacral spine. ${ }^{1,24,58,71}$ The combination of a larger canal diameter with greater mobility of nerve roots suggests that a medially malpositioned lumbosacral pedicle screw will be less likely to cause neurological deficit compared with a screw encroaching upon the thoracic spinal canal. Numerous reports confirm both the greater technical difficulty of placing thoracic-level pedicle screws and the greater risk to neural elements - particularly the spinal cord-should a screw breach the medial wall of a thoracic pedicle and cause stenosis of the spinal canal. ${ }^{26,44,50,55}$ 


\section{B. Calancie et al.}

Two technologies have been developed to help improve the accuracy-and hence the safety-of thoracic pedicle screw implantation. The first involves intraoperative imaging via biplanar fluoroscopy or CT scanning, aiding in either planning the trajectory of a screw path along the pedicle track or the early detection of a malpositioned screw. ${ }^{21,36,63,65,68}$ These approaches show promise but add time and considerable radiation exposure (in the case of CT) to the patient, ${ }^{44}$ without necessarily improving placement accuracy. ${ }^{27,35,50,61}$

The second approach to detect malpositioned thoracic pedicle screws involves intraoperative neuromonitoring, using a technique first developed for monitoring placement of lumbosacral screws. In that original approach,,, 10 a ball-tipped probe routinely used to palpate the pedicle's margins (medial, superior, lateral, and inferior) was modified to act as a stimulating electrode. After cannulation of the pedicle with a pedicle finder/awl, low-intensity stimulating pulses were continuously passed through the insulated probe during palpation of the pedicle track's margins. If there was a breach or a thinning of the pedicle's wall and the probe was adjacent to that region, the stimulating pulses being delivered would depolarize lower motor neuron axons within nearby nerve roots, resulting in stimulus-evoked electromyogram (EMG) responses from target muscles innervated by those nerve roots. Conversely, if the pedicle's bony margins were intact, these same weak stimulus pulses would fail to depolarize nerve root axons due to the higher impedance of the (intact) cortical bone lining the pedicle's walls. By most accounts and based upon its widespread adoption, ${ }^{11,25,31,40,44,57,67}$ this approach was reasonably good at detecting malpositioned lumbosacral pedicle screws.

Attempts to use stimulus-evoked electromyography to assess placement of thoracic-level pedicle screws have been less successful. Using target muscles including intercostals and abdominals, some groups have reported acceptable results, ${ }^{15,16,33,37,53,54,56,64}$ whereas others found the technique lacked sensitivity and abandoned its use. ${ }^{16,38,55,60}$ There are two reasons why the original lumbosacralbased method of monitoring pedicle screw placement may not work as well for pedicle screws placed in the thoracic spine. First, nearly all groups directly stimulate the screw after placement, whereas the original descriptions of this technique emphasized the need to stimulate the pedicle track with a ball-tipped probe before placing the screw. 9,10

The second-and far more critical-difference between the two techniques is the nature of neural tissue encountered with a medially malpositioned screw. In the lumbosacral spine, nerve roots within the cauda equina will be adjacent to a medially malpositioned screw encroaching upon the canal space. In the absence of certain disease states (for example, myasthenia gravis) or excessive neuromuscular blockade, single-pulse stimulation of an intensity sufficient to depolarize a lower motor neuron's axon will always cause an EMG response in that axon's target muscle. In sharp contrast, single-pulse stimulation of upper motor neuron axons, such as those in motor pathways in the spinal cord, rarely leads to evoked motor responses; we know this from transcranial motor evoked potential (MEP) testing, which became practical only after investigators began using a multipulse and high-frequency stimulus pattern to evoke responses from target muscles. ${ }^{8,45}$

Thus we suggest that successful detection of a medially malpositioned screw in the thoracic spine, where the spinal cord would be adjacent to the screw, would be far more likely if one used a pulse-train as the stimulating input and recorded EMG from the natural target muscles of those upper motor neurons in the spinal cord being stimulated: muscles of the lower limbs. The purpose of this study, therefore, was to establish the accuracy of predicting thoracic pedicle screw position based on intraoperative testing of evoked electromyography using a 4-pulse train and lower limb muscles as the main target muscles. Moreover, we sought to define the stimulation intensities that would best detect these defects; these "alarm" values had never been systematically defined in our original lumbosacral neuromonitoring studies, ${ }^{10}$ nor have they been established by other groups for the thoracic spine.

This paper is the first of two reports describing results from this prospective and blinded trial. In this report we present the technical aspects of the monitoring method and provide evidence proving that this method of predicting medially malpositioned screws is much more effective than other neuromonitoring approaches currently in use. In the second paper we describe the role that feedback of our test results to the surgical team played in helping to prevent medial malpositioning of thoracic pedicle screws. ${ }^{7}$ A preliminary report of this study has been published. ${ }^{18}$

\section{Methods}

\section{Patient Group}

Inclusion criteria were: 1) adult patients undergoing an elective procedure (no acute trauma); 2) surgical plan for implantation of pedicle screws within the thoracic spine, including the first lumbar level; 3) manual muscle test scores of at least 2 in major lower limb muscles bilaterally; and 4) ability to provide informed consent.

\section{Anesthesia and Standard Neuromonitoring}

All patients received somatosensory evoked potential (SSEP) and transcranial MEP monitoring, which is considered "standard of care" in our institutions for these types of surgical procedures. Stimulation of ulnar and posterior tibial nerves was used for SSEP monitoring, with recordings from corkscrew electrodes for cortical and subcortical waveforms. Transcranial stimulation of motor cortex was achieved with a Digitimer D185 stimulator, using a 4-pulse train with an interpulse interval of 2 msec. Stimuli were applied through corkscrew electrodes positioned $\sim 1 \mathrm{~cm}$ anterior to $\mathrm{C}-3$ and $\mathrm{C}-4$. Target muscles for MEPs were dependent upon the spinal region being operated upon, but always included hand intrinsics in the upper limbs and tibialis anterior (TA) and abductor hallucis $(\mathrm{AbH})$ in the lower limbs. The "threshold-level" method $^{8}$ was used in all cases to monitor central motor pathway function. Monitoring of both SSEPs (stimulation 


\section{Pulse-train stimulation and thoracic pedicle screws: Part 1}

and recording) and MEPs (recording) was done with a Cadwell Cascade evoked potential device.

The anesthetic protocol was defined by the requirement for MEP monitoring. For more than $90 \%$ of patients, induction was followed by constant infusion of propofol supplemented with nitrous oxide (typically 50\%) and intermittent fentanyl for analgesia. Neuromuscular blockade was used for intubation but was avoided for the remainder of the surgical procedure. During a period of propofol shortage, a small number of procedures were carried out with sevoflurane inhalational anesthesia (maximum 1/2 MAC) supplemented with nitrous oxide, an infusion of dexmedetomidine, and fentanyl as the primary analgesic.

\section{Study Neuromonitoring: Recording}

Bilateral pairs of noninsulated electrodes $(1.2 \mathrm{~cm}$ length) were placed subcutaneously: 1) between ribs 3 and 5 laterally for intercostal muscles (ICs); 2) approximately $5 \mathrm{~cm}$ rostral or caudal to and approximately $8 \mathrm{~cm}$ lateral to the umbilicus for abdominal muscles (Abs); 3) over the rectus femoris and vastus lateralis (Quads); 4) about 5 $\mathrm{cm}$ apart in the tibialis anterior (TA); and 5) about $5 \mathrm{~cm}$ apart in the abductor hallucis $(\mathrm{AbH})$. Electromyographic signals were amplified (gain $=8000)$, filtered $(20-1500$ $\mathrm{Hz}$ ), and stored for later analysis. Digital storage was to magnetic tape (DT1600, Micro Data Instruments) for the first 44 patients, and to computer disk (Power 1401 running "Signal," Cambridge Electronics Devices) for later patients. During initial studies we also recorded EMGs from medial gastrocnemius muscles and output from a single-axis accelerometer affixed to the patient's abdomen (typically visible between support platforms of the Jackson operating table used in all cases). Preliminary analysis showed that these records did not provide any additional useful information, and we will not mention them henceforth. Beyond electromyographic data, we also recorded a voltage signal that corresponded to the current being delivered (see below) through the balltipped probe (where $1 \mathrm{~mA}$ delivered $=100 \mathrm{mV}$ recorded). This signal was generated from a battery-powered accessory box kindly designed and provided to us by Digitimer Ltd. specifically for this purpose.

\section{Study Neuromonitoring: Stimulation}

A Digitimer DS7A stimulator was used to generate and deliver square-wave constant-current pulses to either the pedicle track or the screw. In both cases, stimulation was applied through a ball-tipped probe, with the ball either in the pedicle track or held against the center of the screw shaft after passing through the "crown" of the screw. Pulse duration was always $0.2 \mathrm{msec}$, except for one case in which it was incorrectly set to $1.0 \mathrm{msec}$ (see $R e$ sults). Timing signals for stimulus pulses were generated by a Grass S88X stimulator for the first 44 patients, and from the Power 1401 for later patients. Two types of stimulation were used. 1) We used repetitive 4-pulse trains, with an interpulse interval within each train of $2 \mathrm{msec}$, and an intertrain rate of $3 \mathrm{~Hz}(333 \mathrm{msec}$ between successive 4-pulse trains) for testing pedicle tracks and screws. 2 ) From Case 5 onward, we also routinely used $3-\mathrm{Hz}$ single-pulse stimulation to test pedicle tracks only (we did not use single pulses when testing thresholds to screw stimulation). We restricted the maximum stimulus delivered to $20 \mathrm{~mA}$ and $30 \mathrm{~mA}$ for pedicle track and screw testing, respectively, out of concern for patient safety, as local contractions of arm/hand (for testing T1-3 pedicles) and back/abdominal muscles were sometimes very strong at the higher stimulus intensities used, particularly when stimulating in the pedicle track. In these cases $(n=51$ pedicle tracks), we limited maximum pedicle track stimulation intensity to only $15 \mathrm{~mA}$. This occurred frequently at T-1 $(n=19)$, with most of the remaining cases $(n=26)$ occurring at T-9 through T-12.

In all cases, our primary outcome measure was the minimum stimulus intensity-the threshold-needed to elicit a trace compound muscle action potential from a given target muscle. Each target muscle in a given patient therefore had its own unique threshold (in $\mathrm{mA}$ ) for each pedicle tested. Because we typically monitored 6 muscles from the lower limbs (3 muscles bilaterally), comparisons of "lower limb" thresholds referred to the one muscle of the 6 being monitored whose threshold was the lowest of those 6, unless thresholds of individual muscles were being compared. The lowest threshold in lower limb muscles tended to be among the 3 muscles ipsilateral to the site being stimulated, but this was not always the case. Threshold responses to stimulation were often less than $20 \mu \mathrm{V}$ in magnitude; hence, none of the data figures in Results include any threshold responses, as they would not be visible in the printed record.

\section{Protocol}

Standard operative procedures were followed to expose and place thoracic pedicle screws. From this point onward, and in the companion report, the term "thoracic," with reference to pedicles, includes the first lumbar level (L-1). This is because almost all thoracic constructs caudal to the T-3 levels included L-1, whereas the "traditional" lumbosacral construct rarely extends rostrally beyond the L-3 level. Thus relative to the type of construct, L-1 is much more commonly associated with the thoracic spine than with the lumbar spine. Furthermore, since the spinal cord typically extends caudally through L-1, it was appropriate to include this level in our study, which was designed to develop a more reliable method to protect the spinal cord during placement of pedicle screws.

For all cases, thoracic screws were placed using the "freehand" method, pioneered by Lenke and colleagues and reported to be extremely safe. ${ }^{33}$ After making the initial pedicle track using the pedicle finder (sometimes called the "awl," or "gearshift"), the surgeon used a standard ball-tipped probe to palpate the pedicle track just formed and announced whether a defect in the pedicle wall-suggesting a breach-was evident. If a defect was suspected, the surgeon sometimes used the pedicle finder to revise the trajectory of the pedicle track (that is, redirected), re-palpated, and announced (again) whether the pedicle walls were intact or breached. The surgeon then used a second ball-tipped probe, insulated along its shaft except for the ball-tip itself, to again palpate the walls of the pedicle track for delivery of stimulus pulses. To begin, 


\section{B. Calancie et al.}

the ball-tip was positioned just inside the pedicle track hole (termed "entry point") and repetitive stimulus pulse trains (15 mA intensity) were delivered. In the absence of responses in leg muscles, the probe was advanced along the pedicle track until the ball-tip was judged to be adjacent to the widest part of the spinal canal (termed "midpoint"), the surgeon confirmed that location, and (again in the absence of leg responses) the probe was advanced to the deepest point of the pedicle track (termed "floor"). With the continued absence of leg responses, the stimulus intensity was increased to $20 \mathrm{~mA}$, and the probe was withdrawn to the midpoint.

For the first 40 patients in the study, the surgeon deliberately palpated all aspects of the pedicle track (medial, superior, lateral, inferior, and floor), taking approximately 5 seconds to move the probe along each surface from the entry point to the floor. Beginning with Case 41 , we abandoned this deliberate probing of all aspects of the pedicle track, concentrating instead on taking approximately 5 seconds to move the probe from the entry point to the floor, holding the probe obliquely to press the ball-tip against the pedicle's medial wall. If leg responses were seen at any point during the probing, the surgeon was directed to move the ball tip to the position that maximized the amplitude of the muscle response(s) from the leg muscle(s) and hold it steady at that point, while the stimulus intensity was reduced until the response was extinguished. The stimulus intensity was then increased slightly to confirm the threshold of the response. Thresholds to both 4-pulse and single-pulse stimulation were tested for most pedicle tracks, whereas only 4-pulse stimulation was used to evaluate screw position. Once a given pedicle track was tested, a screw was placed, and the next pedicle track was started. After all pedicle screws had been placed, each was stimulated to a maximum intensity of $30 \mathrm{~mA}$, concluding the intraoperative portion of the study protocol for that patient.

A key aspect of this study's design is that for the first 65 patients the surgeon was not informed of findings related to electrophysiological testing of pedicle track and screw placement (that is, the surgical team was blinded to the test results). However, if pedicle track testing suggested direct contact between the probe and the spinal cord or a nerve root, we informed the surgeon of our findings (broke the blind). The companion paper to this report describes these instances in detail and the overall impact of feedback on screw placement. ${ }^{7}$

\section{Imaging}

Intraoperative fluoroscopy was used to check screw position after all instrumentation was implanted, but before final tightening. Furthermore, an intraoperative CT scanner (O-Arm surgical imaging system, Medtronic) and co-registration of intraoperative images with a neuronavigation system to help define pedicle finder trajectory was used in a small number of patients $(n=6)$, but this activity did not influence our study protocol.

Prior to discharge, patients underwent thin-slice (typically $0.6-\mathrm{mm}$ ) spiral CT imaging of their thoracic spine. Images were reconstructed in the axial and sagittal planes, stripped of identifying features, and-for the first 45 patients - independently graded by 3 readers for at least 2 "passes" through the data. Interrater and intrarater reliability were calculated and found to be comparable to reports from other CT-based studies of pedicle screw position. ${ }^{51,52}$ Subsequent scans were scored by a single reader blinded to patient identity, after statistical analysis showed that this reader had a higher intrarater reliability than the other readers. The magnitude of any medial and lateral breaches of the pedicle was recorded, as was the extent of foraminal encroachment by the implanted screw.

\section{Analysis}

Analysis of intraoperative monitoring data was done off-line at a later time in all cases except for the very first. In the first case, data were collected in real time using a Cadwell Cascade evoked potential machine, but this approach was found to be untenable in the absence of a voice record.

Electromyogram and stimulus current output records were reviewed, and the minimum stimulus current needed to elicit compound muscle action potentials (threshold current) was noted for each muscle and for each stimulation condition (for example, probe vs screw or single-pulse vs pulse train). Results of the surgeon's manual palpation of each pedicle track before stimulation were also noted from the voice record, as were the diameter and length of the screw implanted. Analysis of CT data was done using the Osirix DICOM viewer. Brightness and contrast were adjusted to minimize flare from the screw, but no special filters were used. These settings were adjusted for each patient's images by drawing a line across the widest point of the screw threads and confirming that the line length was within $0.5 \mathrm{~mm}$ of the diameter of that screw.

Since the main goal of this study was to establish the accuracy of intraoperative electrophysiological testing for predicting medially directed screw malpositioning within thoracic pedicles, the receiver operating characteristic (ROC) was the primary analytical tool we used. Multiple breach magnitudes $(\geq 1.0, \geq 1.5$, and $\geq 2.0 \mathrm{~mm})$ and combinations of cutoff stimulus intensities (varied between 4 and $20 \mathrm{~mA}$, in 1-mA increments) were tested (always with 2 cutoff values per ROC analysis). Similarly, we tested: 1) stimulation pattern (single-pulse and 4-pulse); 2) target muscles, including leg muscles (comprising the single lowest threshold of the left/right quadriceps, tibialis anterior, and abductor hallucis), intercostals, and abdominals; and 3) stimulus delivery method (ball-tipped probe stimulating within the pedicle track and stimulation delivered through the implanted screw). The combination of variables returning the largest integral of the ROC curve (or the area under the curve [AUC]) was taken as the best predictor of whether an implanted pedicle screw had breached the medial wall of the pedicle and was encroaching upon the thecal sac.

\section{Results}

We collected intraoperative data from 75 patients (39 male, mean age $[ \pm$ SD] $57.7 \pm 12.5$ years; 36 female, mean age $57.9 \pm 12.6$ years). Three patients did not un- 


\section{Pulse-train stimulation and thoracic pedicle screws: Part 1}

dergo postoperative CT scans to evaluate pedicle screw position. Another patient was tested with an inappropriate stimulus pulse duration of $1.0 \mathrm{msec}$, making comparison of his findings to those from other patients invalid. Thus we obtained useable data from 71 patients. All patients provided informed consent at enrollment in this study, which was approved by the institutional review boards of both Upstate University Hospital and Crouse Hospital (both in Syracuse).

Electrophysiological testing was carried out on a total of 802 implanted screws and a somewhat higher number of pedicle tracks (more pedicle tracks than screw placements were tested because some tracks were revised). Some pedicle tracks $(n=17)$ were not tested, mostly due to: 1$)$ contamination of the ball-tipped probe in one case, requiring resterilization by autoclave; and 2) incorrect connections from amplifiers to the data acquisition device.

Subjects could be grouped into one of 3 categories for surgical indications: 1) cervical decompression and fusion extending caudally to $\mathrm{T}-3 ; 2$ ) correction/fusion of thoracic scoliosis and/or kyphosis; and 3) thoracolumbar fusion. As a consequence, all levels of the thoracic spine were well represented with screw placements. Figure 1 summarizes the numbers of screws placed at each level from T-1 through L-1. The peak in number at T-3 reflects the combination of surgical procedures 1 and 2, while the peak at T-12 reflects the combination of surgical procedures 2 and 3. The lower numbers of screws placed in the midthoracic levels of T6-8 reflects our group's approach-when appropriate- of alternating screws over the middle range of long thoracic constructs (lower screw density) as this is biomechanically acceptable for certain cases, ${ }^{29,48}$ reduces neurological risk, and lowers surgical costs. ${ }^{4,32}$

During manual palpation of the pedicle track for the first 40 patients, we asked our surgeons to palpate all 5 aspects of each pedicle (medial, superior, lateral, inferior, and the floor), taking at least 5 seconds to move the probe along each surface while stimulating pulse trains were being applied. We stopped this practice as it became clear to us that the probability of an evoked response was wholly dependent upon the depth of the probe within the pedicle and unrelated to the position of the ball tip on the pedicle wall at a given depth. Thus all data presented herein related to probe thresholds reflect the lowest absolute threshold encountered, regardless of the probe's medial/lateral or rostral/caudal position within the pedicle track.

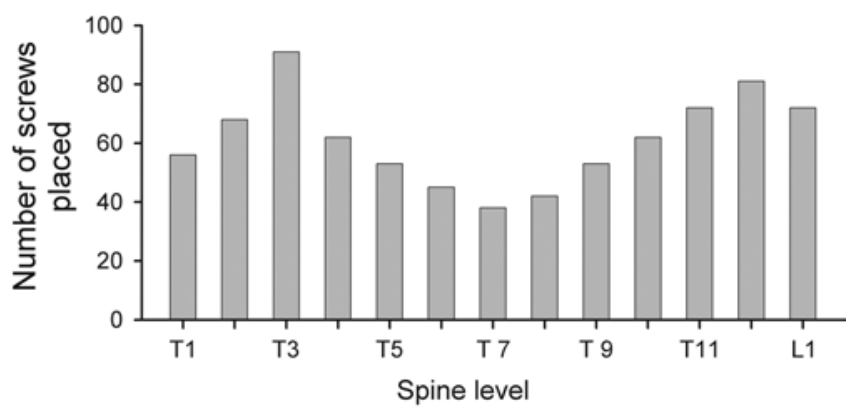

Fig. 1. Bar graph showing numbers of screws placed at each level of the spine for the population studied. The average number of screws implanted per patient was just over 11.
Figure 2 shows the thresholds for probe-based ( $\mathrm{x}$ axis) and screw-based (y-axis) stimulation for all pedicle tracks tested that resulted in an evoked response to probe stimulation in at least one lower limb muscle. All but 3 of the approximately 370 data points in Fig. 2 lie above the dashed line of identity, indicating that thresholds to screw stimulation were almost always higher than, and usually much higher than, thresholds for pedicle track stimulation. Many of the data points in Fig. 2 lie along the upper boundary (30.1 mA) of the y-axis, indicating no response to screw stimulation at the maximum intensity $(30 \mathrm{~mA})$ tested.

Figure 3 shows that the probability of eliciting a response in a particular lower limb muscle (Quads, TA, or $\mathrm{AbH})$ at threshold was strongly related to the level being tested. That is, for levels T-11 through L-1, the Quads were much more likely to have a lower threshold than either the TA or $\mathrm{AbH}$ muscles, whereas the response probability of Quads was much lower for all levels between T-1 and T-10. For these latter levels, the probability of a response from $\mathrm{AbH}$ was equal to (for T-6 and T-8) or higher than that for TA. In fact for the most rostral spine levels tested (T1-4), the probability that $\mathrm{AbH}$ would have the lowest threshold of the 3 lower limb muscles tested was roughly $2 \times$ that of the TA. Table 1 shows a chi-square probability distribution for Quads versus $\mathrm{TA}+\mathrm{AbH}$ and 2 ranges of

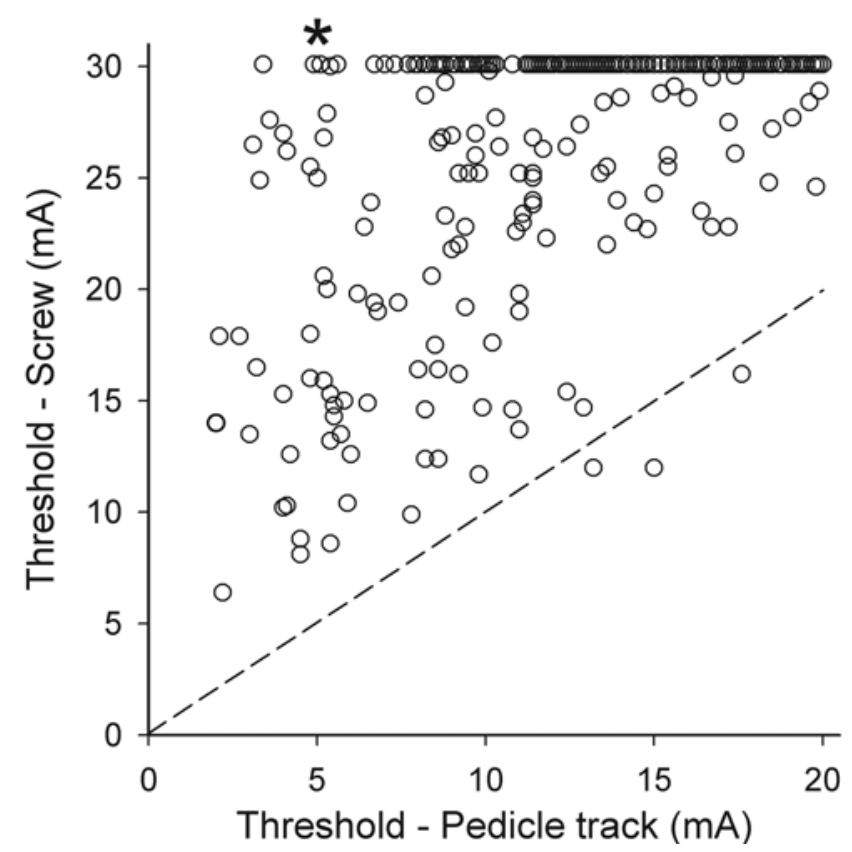

FIG. 2. Minimum stimulus intensity (threshold) that elicited a response in a lower limb muscle when stimulating within the pedicle track via the ball-tipped probe (abscissa) versus the threshold when stimulating via that site's screw (ordinate). Only data points with a response evoked via pedicle track stimulation are included; the maximum pedicle track stimulation intensity was limited to $20 \mathrm{~mA}$. For screws that failed to respond at a maximum stimulus intensity of $30 \mathrm{~mA}$, data points are plotted with a value of 30.1, explaining the many points lined up across the top of the plot. The dashed line of identity shows where all points would lie if their $x$ and $y$ values were the same. In all but 3 cases, the threshold to screw stimulation exceeded that to pedicle track stimulation. The asterisk identifies a single point that is referred to in the Results pertaining to Figure 4. 


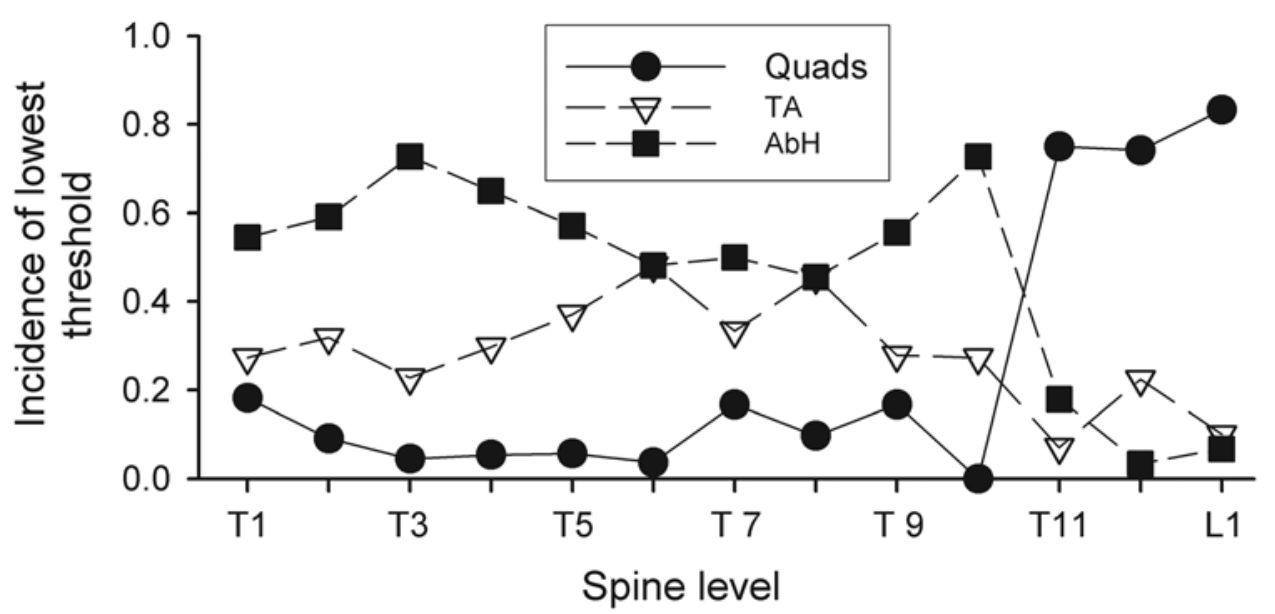

Fig. 3. Response incidence of the single lower limb muscle that demonstrated the lowest threshold to probe-based stimulation within a given pedicle track. In general, quadriceps muscles had a very low probability of having the lowest threshold for levels T-1 through T-10 compared with the other 2 muscles, whereas this probability increased markedly for levels T-11 through L-1. The $\mathrm{AbH}$ response incidence was roughly the opposite to that of quadriceps, being highest for the rostral thoracic spine, and lowest for the caudal thoracic and L-1 levels.

spine levels (T1-10 vs T11-L1). The distribution of Quads versus $\mathrm{TA}$ and $\mathrm{AbH}$ as showing the lowest thresholds to probe stimulation was significantly different $(\mathrm{p}<0.0001$, Fisher exact test) for caudal (T11-L1) versus other levels (T1-10) of the thoracic spine.

Moving now to screw positions, Fig. 4 shows an example of a left-side screw at the T-5 level that breached the medial pedicle wall, with a measured encroachment of $2.1 \mathrm{~mm}$ (Fig. 4C). Prior to screw implantation, stimulation of this pedicle track with the ball-tipped probe resulted in EMG responses from the left-side Quads, TA, and $\mathrm{AbH}$ at low intensities (responses to $7.4 \mathrm{~mA}$ shown in Fig. 4A), and a threshold stimulus intensity (in $\mathrm{AbH}$; not shown) of $5.1 \mathrm{~mA}$; this probe and screw threshold pair is noted with an asterisk in Fig. 2. In the example shown in Fig. 4, it was not uncommon for screws with clinically relevant medial breaches to not evoke lower limb EMG responses when stimulated at intensities of $30 \mathrm{~mA}$ (or 31 $\mathrm{mA}$, as in this case; Fig. 4B).

Although the absolute threshold intensity to evoke EMG responses from lower-limb muscles was almost always lower for pedicle track stimulation than for screw stimulation (as shown in Fig. 2), there was a clear relationship between the medial/lateral position of a screw and the probability of seeing an evoked response to stimulation of both the pedicle track (that is, via the probe) and the subsequently placed screw. This is summarized in Fig. 5, illustrating response probabilities from leg muscles to probe-based pedicle track and screw stimulation grouped by position of the medial-most threads of the

TABLE 1: Probability distribution for muscle group vs spine level, based on the lowest threshold to pedicle track-based stimulation

\begin{tabular}{rcc}
\hline Level & Quads & TA + AbH \\
\hline T1-10 & 20 & 247 \\
T11-L1 & 114 & 32 \\
\hline
\end{tabular}

screw relative to the pedicle's medial cortical wall. In all cases, the probability of a response to stimulation of the pedicle track with the ball-tipped probe (that is, before the screw was placed) was considerably higher than the probability of a response to screw stimulation. While it comes as no surprise that a screw placed lateral to the pedicle's medial wall (left-most data points in Fig. 5) was unlikely to elicit a lower-limb response when stimulated-even at intensities as high as $30 \mathrm{~mA}$-roughly one-third of the 32 screws with measured medial breaches of $2 \mathrm{~mm}$ or more still failed to evoke EMG responses from leg muscles when stimulated (right-most triangle of Fig. 5; see Fig. 4B for individual example). In sharp contrast, probe stimulation of the pedicle tracks giving rise to screw breaches of $2 \mathrm{~mm}$ or more in magnitude evoked EMG responses from leg muscles in $100 \%$ of the cases seen (probability of 1.0, as shown in Fig. 5; right-most circle).

Fig. 6 shows the distribution by spine level of screws with clinically significant $(\geq 2 \mathrm{~mm})$ medial malpositioning. There was a clear preponderance of significant medial malpositioning in the T-12 and (especially) L-1 levels, whereas none was encountered among the sum of 124 screws placed at the T-1 and T-2 levels. This trend must reflect, at least in part, the significant difference in screw diameters used at these different levels. Screws of 4.0 $\mathrm{mm}$ and $4.5 \mathrm{~mm}$ diameter were typically used in T-1 and T-2, respectively, whereas L-1 screws were-in the early stages of this study-typically 6.0 or $6.5 \mathrm{~mm}$ in diameter. In fact, after it was pointed out to our surgical team early on in this study that in some cases the same screw placed perfectly down the center of the L-1 pedicle was showing both medial and lateral breaches in the pedicle, smallerdiameter screws (typically $5.5 \mathrm{~mm}$ ) were subsequently used in the L-1 pedicle.

Other groups using stimulus-evoked electromyography to monitor thoracic pedicle screw placement have used muscles innervated by the roots exiting adjacent to the spinal levels being instrumented as their targets. In keeping with that approach, we also measured stimulus- 
A Probe stimulation $(7.4 \mathrm{~mA})$

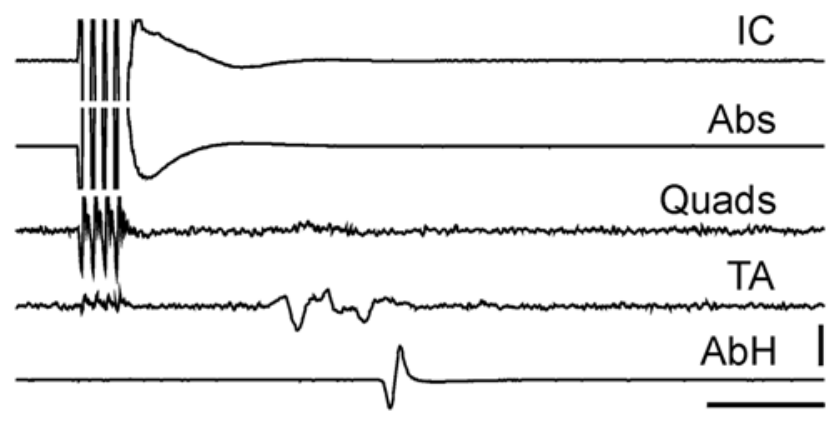

\section{B Screw stimulation (31 $\mathrm{mA})$}

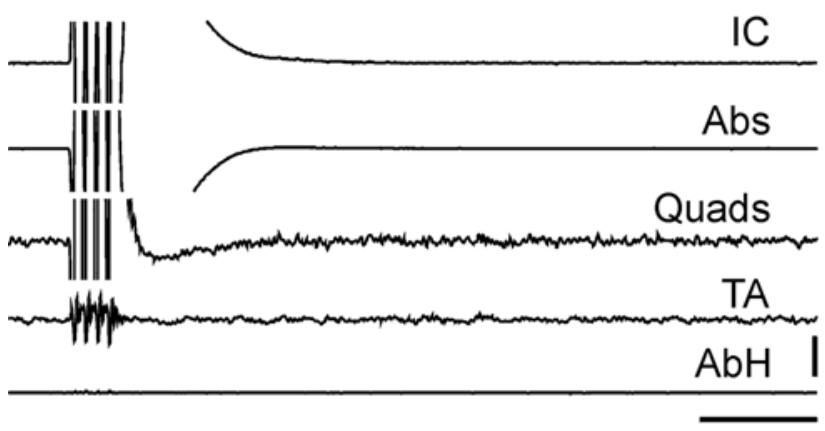

\section{Axial CT image of T5}

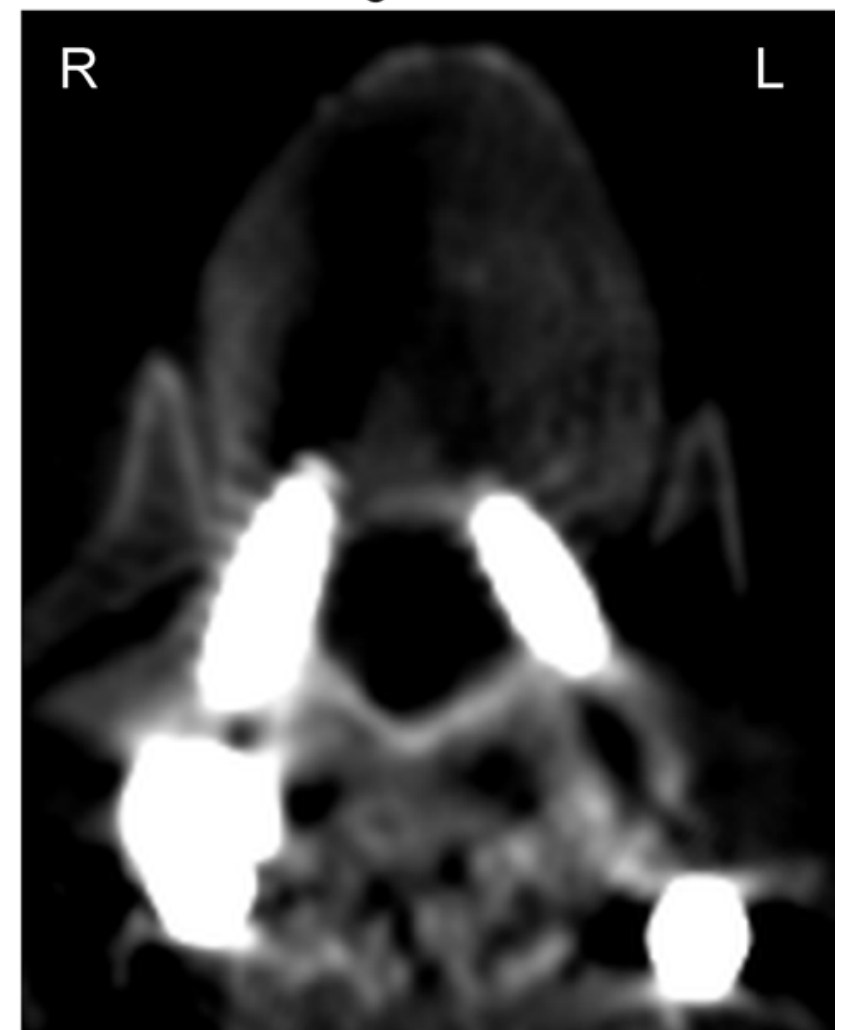

Fig. 4. Example showing evoked EMG responses in multiple leg muscles following pedicle track stimulation through the probe (A) using a 4-pulse train and 7.4-mA stimulus intensity. There is a trace response in the quadriceps (Quads), a somewhat larger response from tibialis anterior (TA), and a much larger response from the abductor hallucis ( $\mathrm{AbH})$. In this example, $7.4 \mathrm{~mA}$ was the threshold for the Quads, and it was well above the threshold for the $\mathrm{AbH}(5.1 \mathrm{~mA}$; not shown). Stimulation of a screw placed into this pedicle track failed to evoke EMG activity from any of the leg muscles (B), even when a much stronger stimulus intensity ( $31 \mathrm{~mA}$ ) was used. An axial CT image of the T-5 pedicle (C) shows that the left-side screw (toward the right side of the image) was deviated medially and encroached upon the spinal canal. Note that the "flare" in this image exaggerates the apparent size of the screws; the image was generated in this way to better visualize the cortical margin of the spinal canal. Vertical bar for EMG $=2.5 \mathrm{mV}$ for intercostals (IC), abdominals (Abs) and AbH, and $0.25 \mathrm{mV}$ for Quads and TA. Horizontal calibration bar $=20 \mathrm{msec}$.

evoked thresholds of intercostal and abdominal muscles for most of the sites tested. Figure 7 summarizes the average thresholds for lower limb, intercostal, and abdominal muscles in response to pedicle track stimulation and grouped by medial/lateral screw position (as for Fig. 5). Beginning with responses from leg muscles (dark gray bars), the average threshold was highest for screws whose threads were lying lateral to the pedicle's medial wall, but this average was heavily dominated by cases in which no response was seen at the maximum stimulus intensity tested (a value of $20.1 \mathrm{~mA}$ was used for nonresponders to pedicle track stimulation when calculating the means of all screws in this category). As the breach magnitude extended medially into the canal, the average threshold for evoking responses from one or more lower limb muscles via pedicle track stimulation declined to a low of approximately $7 \mathrm{~mA}$ (with minimal variance compared with other averages) for medial breaches of $2 \mathrm{~mm}$ or more (right-most dark gray bar of Fig. 7).

Figure 7 further shows that average thresholds for intercostal (light gray bars) and abdominal (black bars) muscles demonstrated much greater variability than those for lower limb muscles (as judged by error bar magni- tudes). Moreover, the relationship between the probe's proximity to the medial wall was not linearly related to threshold, as it was (roughly) for lower limb muscles. Thus, probe thresholds for pedicle tracks whose screws were lying furthest lateral to the medial wall were lower, on average, than those whose screw threads were either flush with the pedicle's medial wall, or for when screws had breached the pedicle wall and were now encroaching slightly $(0.4-0.9 \mathrm{~mm})$ into the canal. It was only for the more pronounced medial breaches $(1.0-1.9 \mathrm{~mm}$ and $\geq 2$ $\mathrm{mm}$ ) that average thresholds for intercostal and abdominal muscle groups were lower than their counterparts for lateral-lying pedicle tracks. Even so, and as the right-most bars of Fig. 7 show, even the largest medial breaches resulted in intercostal and abdominal average thresholds well above those for lower limb muscles, and the variance for the former 2 target muscle groups was much higher than that for lower limb muscles.

Other than knowing that overall thresholds to probe stimulation are much lower-on average-for pedicle tracks leading to significant medial breaches of the implanted screw, there is no way from the data summarized in Fig. 7 to know what to do about an individual pedicle 


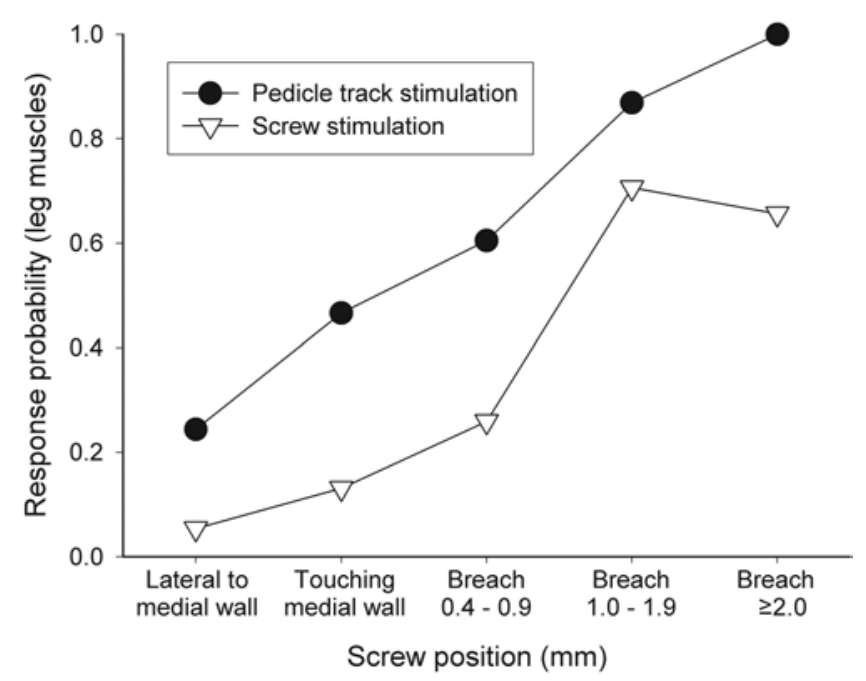

FIG. 5. Summary of lower limb EMG response probability to both probe-based pedicle track and screw stimulation grouped by the position of the medial edge of the screw with respect to the outer margin of the pedicle's medial wall (equivalent to the lateral-most margin of the spinal canal). Of the 5 data points along the $x$-axis, the 3 positions to the right all indicate some degree of medial breach, while screws clearly physically removed from the pedicle's medial wall are grouped in the left-most section of the figure. Not surprisingly, these "lateral" sites show the lowest probability of eliciting a response up to the maximum stimulus intensity tested (usually $20 \mathrm{~mA}$ for pedicle track stimulation and $30 \mathrm{~mA}$ for screw stimulation). As the trajectory of the pedicle track approached the medial wall of the pedicle, the probability of a response increased consistently for stimulation within the pedicle track, until the probability was 1.0 for pedicle track testing at those sites that, after screw placement, resulted in clinically relevant (that is, $\geq 2.0 \mathrm{~mm}$ ) medial encroachment. The probability of eliciting a lower-limb response to pedicle track stimulation was greater than that for screw stimulation for each of the 5 categories of screw position shown.

track that tests with a low threshold to lower limb EMG. Put another way, is there a particular pedicle track-based stimulus intensity-an alarm value-below which predicts a significant medial breach of the screw with a high level of accuracy, and above which is consistent with a safe screw placement? Moreover, does this alarm threshold vary by level within the thoracic spine?

To answer the former question, we adopted an ROC analysis, plotting the true-positive rate (sensitivity) against

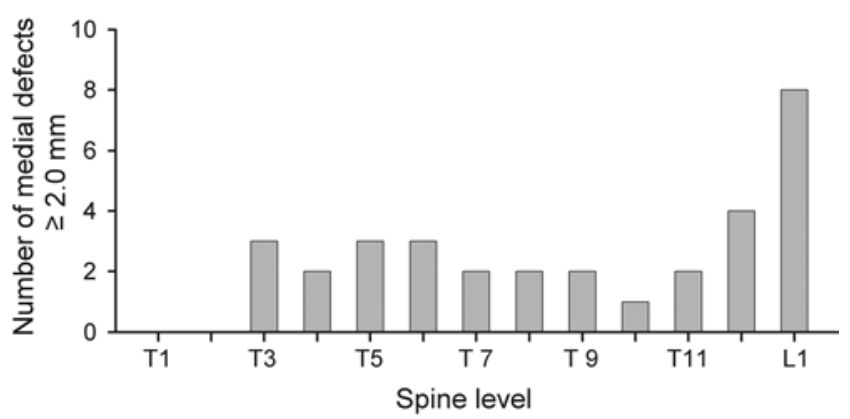

FIG. 6. Bar graph showing the distribution of screws with a measured medial pedicle breach equal to or exceeding $2 \mathrm{~mm}$ in magnitude, from a total of 32 such cases. The highest incidence was at the L-1 level, whereas there were no cases of clinically relevant medial breaches of screws placed at the T-1 or T-2 levels. the false-positive rate (1 minus specificity) for probe or screw stimulation, using different stimulus intensities as cutoff values and the magnitude of a medial pedicle breach by a screw as the variable being detected. For this approach, we did not stratify findings by level; all data were lumped together in a single analysis. When using the lower limbs for target muscles, we used the single lowest threshold of the 6 muscles being monitored.

Figure 8 shows 4 different ROC curves that best summarize our findings using different muscle groups (lower limbs vs abdominals vs intercostals) and different means of stimulation (ball-tipped probe vs screw) for detecting a medial breach $2 \mathrm{~mm}$ or greater in magnitude. While the conditions vary, this approach allows us to directly compare the area under the curve (AUC), whereby higher values indicate a stronger predictive value of the test. The study combination that returned the highest AUC (0.93) used probe stimulation with a 4-pulse train, EMG from lower limb muscles, and stimulation cutoffs of $10 \mathrm{~mA}$ and $15 \mathrm{~mA}$. Note that the $15-\mathrm{mA}$ cutoff point lies at a value of 1.0 on the "True Positive rate" axis, indicating that none of the pedicle tracks giving rise to medial breaches of 2 $\mathrm{mm}$ or more went undetected with this $15-\mathrm{mA}$ stimulus intensity. Several other combinations of cutoff thresholds (for example, 9 and $14 \mathrm{~mA}$ ) returned AUC values that matched the curve shown in Fig. 8 (pedicle track + lower limbs). The next highest AUC (0.79) seen was for screw stimulation and leg target muscles, but this approach had much lower values for sensitivity (screw stimulation often failed to elicit a response, as shown in Figs. 2 and 4). Finally, probe stimulation using intercostals or abdominals as target muscles resulted in identical AUC values (0.71), yet the shapes of the ROC lines for both outcome measures yielding the maximal AUC values were quite different.

The results presented thus far have been restricted to screw malpositionings that were medial to the pedicle wall (leading to varying degrees of canal encroachment). We also categorized and analyzed lateral screw placements in the first 40 cases studied. Receiver operating characteristic analysis of intercostal and abdominal EMG responses to screw stimulation for detecting lateral defects of $2 \mathrm{~mm}$ or more in magnitude led to AUC values of 0.61 . We have since stopped our analysis of lateral thoracic pedicle breaches, because they pose no foreseeable risk to the spinal cord.

During testing of a small number of pedicle tracks $(n=8)$, we encountered very low thresholds for evoking EMG responses from leg muscles, and at the time we suspected these to be medially directed pedicle tracks that would likely lead to medial defects in the pedicle wall after screw placement. However, postoperative CT analysis revealed each of these low thresholds to be due to screws traversing the neural foramen at that level. An example is shown in Fig. 9, where the left T-5 screw is seen on the CT image to be obscuring the foramen. Stimulation through the probe placed along the pedicle track resulted in EMG responses at a threshold intensity of $6.7 \mathrm{~mA}$ (from the left $\mathrm{AbH}$; not shown). At the higher stimulus intensity shown (14.9 mA; Fig. 9 lower), there was a strong bilateral recruitment of lower limb muscles; this bilateral recruitment pattern was evident in 7 of the 8 foraminal defects seen. 


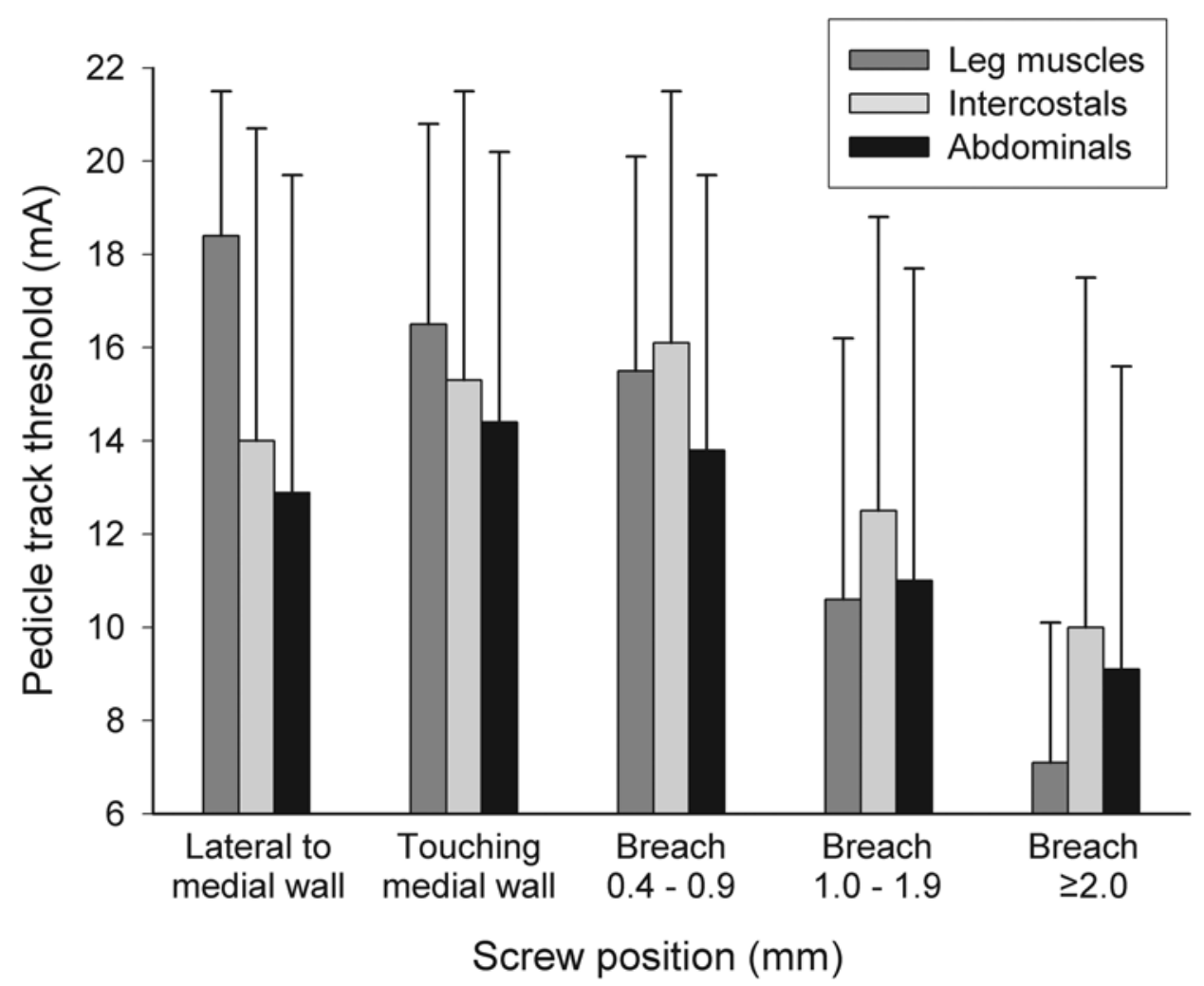

FIG. 7. Average threshold of 3 muscle groups (legs, intercostals, abdominals) to probe-based stimulation of the pedicle track, grouped by final screw position as described in the legend for Fig. 5. For the leg muscles, the single lowest threshold of the 6 muscles being monitored for that site was used in the calculation. A value of $20.1 \mathrm{~mA}$ was used in these calculations if there was no response to testing at the maximum intensity used $(20 \mathrm{~mA})$ for a given pedicle track. For legs, the highest thresholds were seen when the final screw position was lateral to the pedicle's medial wall, and the lowest thresholds were seen when the screw showed a clinically relevant $(\geq 2.0 \mathrm{~mm})$ medial breach. The relationship between pedicle track threshold and final screw position was less predictable for the intercostals and abdominal muscles. For these latter muscle groups, while thresholds also were lowest on average for clinically relevant medial breaches, the variance in this measure was much higher than that seen for leg muscles. Error bars indicate SDs.

The mean threshold for these pedicle tracks encroaching on a neural foramen when tested with pedicle track stimulation was $6.7 \pm 2.4 \mathrm{~mA}$, yet all but 2 screws were clearly lateral to the pedicle wall (the 2 exceptions had only minimal canal encroachment of $0.4 \mathrm{~mm}$ ). Each of these placements contributed to the "false positive" categories within the ROC analysis of Fig. 8 (pedicle track + lower limbs). Stimulation of these foraminally placed screws resulted in a mean threshold to lower-limb EMG responses of $23.0 \pm 6.6 \mathrm{~mA}$, but note that responses were elicited from only 4 of these 8 screws; the remaining 4 screws did not evoke lower-limb EMG responses even at the maximum stimulus intensity $(30 \mathrm{~mA})$ tested.

To this point, we have shown that the approach combining pedicle track-based 4-pulse stimulation with leg target muscles is far more reliable for predicting medially malpositioned pedicle screws than single-pulse stimulation and either intercostal or abdominal EMG monitoring. But is a 4-pulse train necessary for this approach to be effective? The answer is "yes." The CT image in Fig. $10 \mathrm{~A}$ shows an example involving pedicle track stimulation at a site (left T-8) that led to a medial breach by the screw. Below that image are shown progressively-weaker responses elicited in multiple lower limb muscles as the number of supra-threshold pulses in a stimulus train delivered to this T-8 pedicle track was decreased from 4 to 1 (Fig. 10B-E), even though the stimulus intensity (20 mA) never varied. In contrast, evoked responses for stimulation at nearly all T-11 through L-1 pedicle tracks were unchanged whether a pulse train or single-pulse stimulation was used, provided the stimulus intensity remained constant. An example is shown in Fig. 10F (right L-1 medial malpositioning). Stimulation within this L-1 pedicle track led to a primary response (in Quads) that was largely unchanged whether using 4-, 3-, 2-, or single-pulse stimulation (Fig. 10G-J), provided the stimulus intensity (in this case, $5 \mathrm{~mA}$ ) remained constant.

We routinely shifted between single- and 4-pulse stimulation for testing most pedicle tracks. In only 2 of the 75 patients in this study did we see repeated responses in one or more leg muscles to single-pulse stimulation when testing a pedicle track rostral to T-11. For the 11 pedicle tracks in these 2 patients where this was seen, thresholds to 4-pulse and single-pulse stimulation were roughly equal. In 5 of these 11 instances, thresholds were between 8 and $10 \mathrm{~mA}$-below the 10 -mA cutoff we adopted for ROC analysis. In each instance, the resulting screw placement did not encroach upon the spinal canal, 


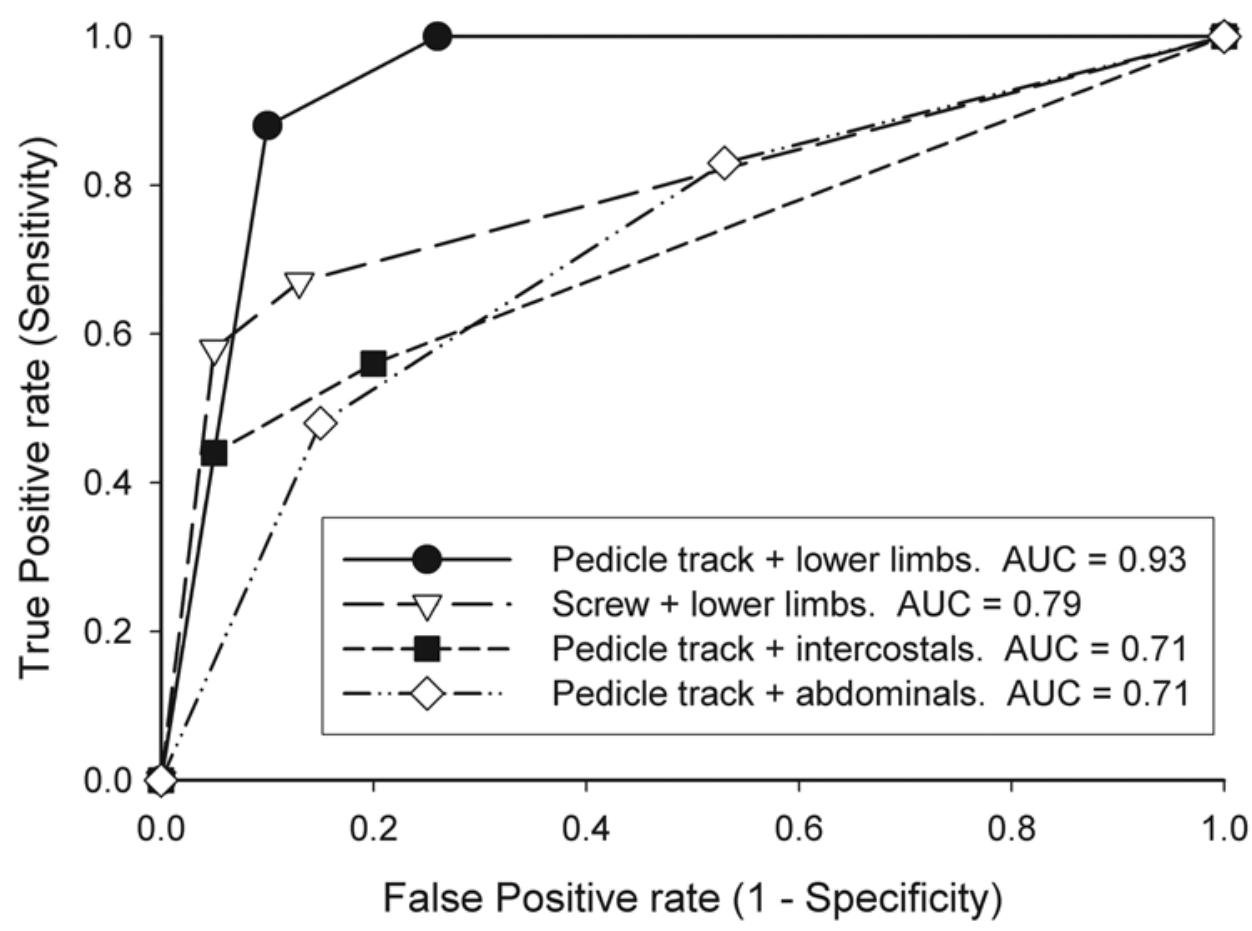

FIG. 8. Receiver operating characteristic curves summarizing the ability for different combinations of stimulus intensities to predict (for pedicle track stimulation) or detect (for screw stimulation) pedicle screws with clinically relevant $(\geq 2 \mathrm{~mm}$ ) medial breaches. Four different curves are shown, each reflecting either pedicle track or direct screw stimulation and one of 3 different target muscle groups: lower limbs (quadriceps, TA, AbH), or intercostals, or abdominals. Probe-based stimulation of the pedicle track and EMG from leg muscles was the most accurate for predicting a clinically relevant medial pedicle breach, with a total AUC of 0.93 . The stimulus intensities used to define the 4 curves were 10 and $15 \mathrm{~mA}$ for pedicle track stimulation and lower limbs, 21 and $29 \mathrm{~mA}$ for screw stimulation and lower limbs, 4 and $8 \mathrm{~mA}$ for pedicle track stimulation and intercostals, and 5 and $15 \mathrm{~mA}$ for pedicle track stimulation and abdominals. In all cases these lower and upper stimulus intensities returned the highest AUC for that combination of stimulation site and target muscle.

suggesting a condition of spinal cord hyperexcitability in these 2 patients (one had concomitant multiple sclerosis) that might require adjustment of the cutoff threshold recommendations (see Discussion).

\section{Discussion}

Compared with the lumbar spine, the safe placement of thoracic pedicle screws is more challenging, because the pedicles are narrower and there is greater anatomical variation by level. ${ }^{26,44,50,55}$ The overall incidence of neurological symptoms attributed to malpositioned screws in the early postoperative period ranges from $0.31 \%$ to $8.3 \%,{ }^{17,23,69,70}$ yet reports of permanent paraplegia arising from thoracic screw malpositioning are rare. Even when the entire diameter of a screw is in the spinal canal, it is possible for the patient to be symptom-free, at least in the short term after implantation. ${ }^{39}$ As neuromonitorists, we are frequently reminded by surgeons that earlier methods of thoracic spine instrumentation relying upon sublaminar hooks routinely caused stenosis of $2 \mathrm{~mm}$ or more at multiple sites within the spinal canal, without significant neurological consequences. ${ }^{46}$ Given these facts, why even bother with neuromonitoring for screw position?

First, the rates of neurological compromise associated with earlier thoracic spine surgeries, before pedicle screws were used, are considerably lower $(0.55 \%)^{42}$ than many of the rates reported more recently for thoracic pedicle screw implantation, as summarized above. Unless dislodged during a corrective procedure, a sublaminar hook will always introduce a constant amount of canal stenosis-typically no more than $2 \mathrm{~mm}$. Conversely a pedicle screw could cause much greater amounts of canal stenosis, depending upon the trajectory of the screw. Second, evidence is accumulating that while neurological symptoms of medial screw malpositioning might not manifest in the early postoperative period - a time typically associated with a period of limited mobility-signs of canal stenosis may emerge weeks, months, or even years later in the form of headache or dizziness (suggesting dural erosion and CSF leak or meningeal irritation) and pain or weakness (indicating myelopathy). ${ }^{2,39,43,47}$ The good news is that surgical removal of the offending screw often can resolve symptoms, even one or more years after screw implantation. ${ }^{39}$ Finally, not all experts agree that the spinal cord can tolerate canal stenosis of up to $4 \mathrm{~mm}^{46}$ without consequences, particularly if that stenosis is caused by the relatively sharp threads of a malpositioned pedicle screw., ${ }^{3,62}$ For all these reasons, we believe it is appropriate and necessary to develop improved methods for detecting and preventing medial malpositioning of thoracic-level pedicle screws. As Marc Nuwer and colleagues wrote almost 2 decades ago about how neuromonitoring reduced neurological deficits after scoliosis surgery: “... 

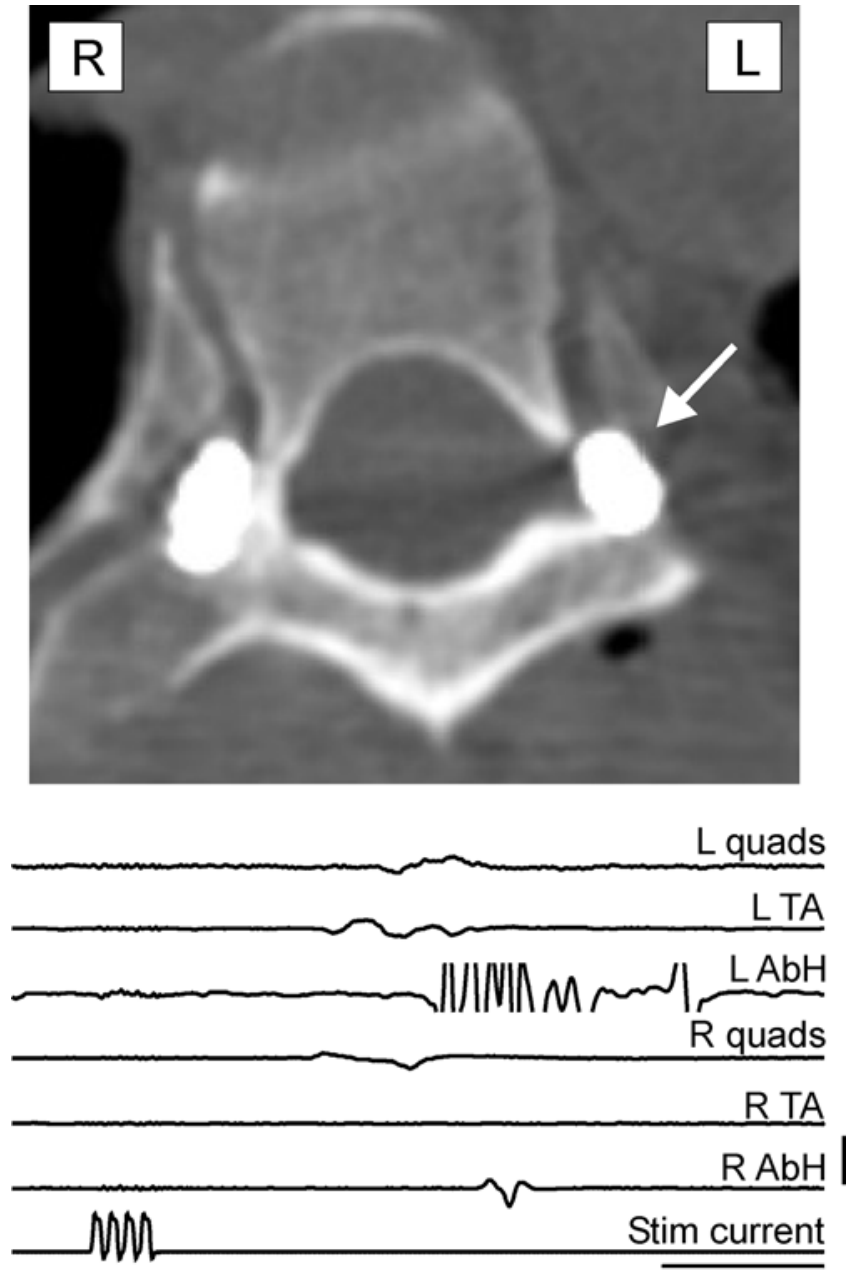

FIG. 9. Upper: CT scan (axial cut) showing example of a screw at the left-side T5 level whose trajectory was too far inferior to the pedicle, so that it ended up spanning the neural foramen at the T5/T6 level. Stimulation (stim) of the pedicle track before screw placement resulted in EMG responses from multiple leg muscles at a threshold as low as 6.7 mA (for left AbH). Lower: EMG was evoked from all left-side and 2 right-side muscles following stronger stimulation $(14.9 \mathrm{~mA})$. Vertical calibration bar $=0.25 \mathrm{mV}$ for all EMG records. Horizontal calibration bar $=20 \mathrm{msec}$. $\mathrm{L}=$ left; $R=$ right.

the best and most cost effective way to treat paraplegia is by preventing it in the first place."'42 Finally, and like numerous other authors, $, 320,23,49,50,59,62$ we have adopted a medial breach alarm level of $2 \mathrm{~mm}$ or more as a clinically relevant breach magnitude, a degree of encroachment that should be avoided whenever possible.

\section{How Do Results of the Current Study Compare with Other Neuromonitoring Reports?}

A number of studies of stimulus-evoked electromyography for the neuromonitoring of thoracic screw placement have found the approach to be unsatisfactory. ${ }^{16,38,55,60}$ The authors of one of these studies wrote: "EMG does not appear to be a reliable means for detection of medial cortical breaches when placing pedicle screws in the thoracic spine of patients with AIS [adolescent idiopathic scoliosis]." 60 That study used single-pulse stimulation, with intercostal and abdominal muscles as targets. It is not clear whether stimuli were delivered to the pedicle track via a ball-tipped probe, but screw stimulation was definitely used in that study. ${ }^{60}$ With a reported sensitivity of only 0.28 to medial defects of $2 \mathrm{~mm}$ or more in magnitude, ${ }^{60}$ it is hard to argue with the conclusions of that study.

In contrast, several other groups have reported results of thoracic pedicle screw testing that-while generally less reliable than seen with testing of lumbar pedicle screw placements-were judged by their authors to be satisfactory nonetheless. ${ }^{15,16,33,37,53,54,56,64}$ Specifically in reference to two of the conflicting studies, ${ }^{53,55}$ Finkelstein was perplexed because "... the studies pose the same question, evaluate the same outcome, and yet come to diametrically opposite conclusions." 22 Indeed, the authors of one of the more recent studies using single-pulse screw stimulation and EMG monitoring from intercostals reported false-negative and false-positive rates of $10 \%$ and $66 \%$, respectively, yet wrote: "In conclusion, assessment of upper thoracic pedicle screw placement (T2-6) by recording triggered EMG thresholds at a single pair of axillary electrodes was highly reliable." 54 We cannot understand how a technique that 1) misses real problems $10 \%$ of the time and 2) generates a false alarm for 2 of every 3 screws placed could realistically be considered "highly reliable."

In comparison with these other studies, our findings showed both high sensitivity (that is, the ability to detect real events) and specificity (that is, few false alarms) for predicting medially malpositioned screws, provided that 4-pulse stimulation was delivered through the ball-tipped probe held in the pedicle track and target muscles in the legs were used. Any "lesser" combination, such as using single-pulse stimulation or screw stimulation (see below), or using abdominals and/or intercostals as target muscles, led to a pronounced deterioration in our ability to successfully predict medially malpositioned screws.

One consideration regarding screw stimulation requires special mention. We found that a positive response in one or more leg muscles to screw stimulation at a relatively low threshold (for example, $<20 \mathrm{~mA}$ ) was almost always predictive of a significant medially malpositioned thoracic pedicle screw. However, we also encountered many cases in which stimulation of screws proven to have significant canal encroachment failed to elicit any EMG response in lower-limb muscles. Overall, the sensitivity to medial breach via screw stimulation was much lower than it was for stimulation within the pedicle track (before the screw was placed). While this undoubtedly reflects the lower current density associated with stimulation through the screw compared with the ball-tipped probe, we recently showed that the conductive properties of the titanium-alloy screws used in the constructs we tested also play a role in limiting the ability of direct screw stimulation to detect medial malpositioning. ${ }^{19}$ For testing thoracic pedicle screw placement, then, it is imperative that the pedicle track be adequately tested with stimulation before the screw is placed. Not only have we proven this to be a more accurate predictor of screw position, but if one waits until the screw has already been placed before testing, it is possible that a significant medial misdirection of the screw may have already caused neural injury. We just do not see any valid reason for stimulating the screw 
B. Calancie et al.

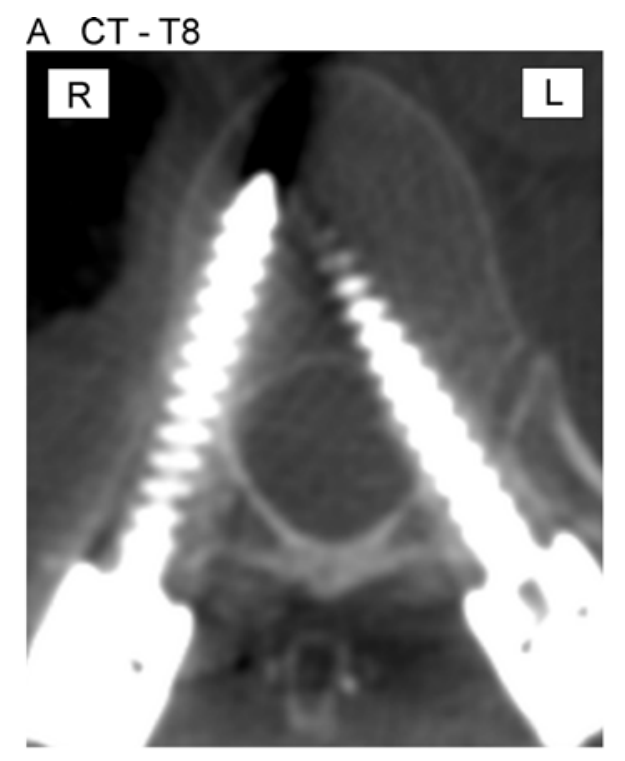

F CT - L1
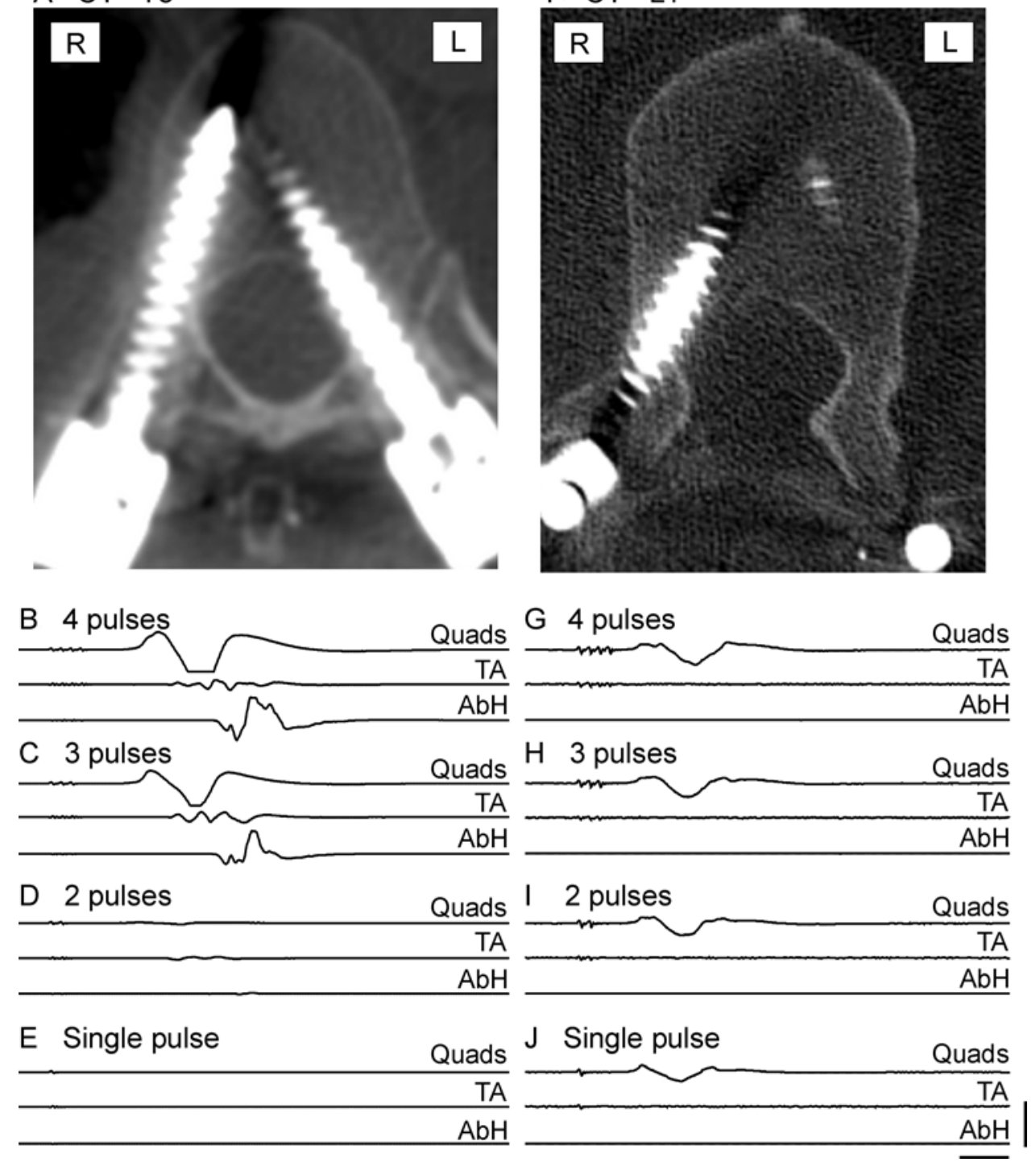

FIG. 10. CT scans (A and F) and evoked responses from leg muscles mediated by either spinal cord stimulation (B-E) or nerve root stimulation (G-J). In both examples, stimulation was via a pedicle track that was biased medially, so that placement of a screw along that track resulted in a minor medial screw malpositioning, as shown in the CT scans. Strong (20 mA) 4-pulse pedicle track stimulation at T-8 evoked responses in multiple leg muscles (B) that were little-changed in response to a 3-pulse stimulus train (C). However, a 2-pulse train elicited only trace responses in all 3 muscle groups, even though the same $20-\mathrm{mA}$ stimulus intensity was used. Stimulation with a single 20-mA pulse failed to evoke any EMG response from the leg muscles. In contrast, the quadriceps response to 5 -mA stimulation of the right L-1 pedicle track using a 4-pulse train was little changed as the number of pulses in the train decreased from 4 pulses down to a single pulse $(G-J)$. Vertical calibration bar $=1.25 \mathrm{mV}$ for $B-E$, and $0.5 \mathrm{mV}$ for $\mathrm{G}-\mathrm{J}$; horizontal calibration bar $=20 \mathrm{msec}$.

in lieu of pedicle track stimulation with the ball-tipped probe, especially since the freehand method calls for the surgeon to palpate the pedicle walls with a ball-tipped probe anyway, during which stimulation could be applied through the probe. We will continue to test screws with direct stimulation after implantation, but only to detect the rare cases of pedicle "blow-out" caused by the screw implantation.

Is There an Optimal Threshold (Alarm) Intensity for Predicting Medial Screw Malpositioning?

The ROC analysis showed that the combination of
10-mA (lower cutoff) and 15-mA (upper cutoff) stimulus intensities combined with 4-pulse stimulation within the pedicle track and targeting leg muscles provided the greatest overall accuracy for predicting medial malpositioning of thoracic pedicle screws. It is especially noteworthy that of the 32 screws placed in this study with a medial defect equal to or exceeding $2 \mathrm{~mm}$, each and every one was correctly predicted with these 2 cutoff thresholds. Since for this type of surgery the consequences of a false negative can be severe (significant canal stenosis), we believe it is more important, on balance, for a diagnostic test to detect real events (that is, minimize false 


\section{Pulse-train stimulation and thoracic pedicle screws: Part 1}

negatives) at the inevitable expense of generating more false-positive outcomes.

As a reminder, the ROC analysis does not consider potential differences in threshold cutoffs based upon the level of the spine being tested, or upon the amount of risk (or risk avoidance) of an error in detection that the surgical team is willing to tolerate. In practice, there may not be a single "optimal" testing intensity at all. Whereas our group has adopted a 10-mA testing intensity as our alarm level for a given patient, other groups are free to choose otherwise. For example, more conservative users-who might be willing to tolerate a higher incidence of falsepositive outcomes to lower the risk of missing a significant (for example, $>2 \mathrm{~mm}$ ) medial malpositioning of a screw-might choose a $12-\mathrm{mA}$ test intensity rather than a $10 \mathrm{~mA}$ value. This is a decision that should be made jointly by the surgical and neuromonitoring teams. One could anticipate that a surgeon with relatively little experience placing thoracic-level pedicle screws might want to use the 12-mA testing intensity, to better guard against a significant medial malpositioning. A more experienced surgeon, conversely, might feel comfortable using a weaker intensity as an alarm cutoff, thereby avoiding the greater numbers of false positives that would invariably occur when using a stronger test intensity. This decision might also be better informed after considering the role that feedback of our intraoperative testing played in the avoidance of significant medial screw malpositionings; these data are contained in the companion report. ${ }^{7}$

\section{Does the Threshold Alarm Vary by Spine Level?}

Not in any consistent way, as far as we can tell, based on a level-by-level examination of sensitivity and specificity (data not shown). However, our data set was incomplete, in that despite placement of more than 120 screws at T- 1 and T-2, there was not a single medially malpositioned screw at these levels. There is no reason to suspect that a $10-\mathrm{mA}$ intensity would not be appropriate for testing at T-1 and T-2, since this alarm level was very effective for predicting pedicle tracks that eventually led to clinically relevant screw malpositionings at nearby levels (for example, T-3 and T-4). Thus we use $10 \mathrm{~mA}$ as a cutoff intensity for warning of excessive medial bias in the pedicle track trajectory across all levels of the spine, including T-1 and T-2, but acknowledge that this approach may change as we continue to accrue data.

\section{Is There any Benefit to Monitoring Intercostal or} Abdominal Muscles?

We included intercostals and abdominals as target muscle groups to be consistent with the approach taken in most neuromonitoring studies of thoracic pedicle screw placement. The electrode positions we used for intercostals (between the second and fifth rib laterally) probably limited their range to T-1 through T-6, whereas abdominal electromyography electrodes were responsive to stimulation at the levels of T-6 through L-1. Given this spatial separation, we conducted ROC analysis independently for these 2 target muscle groups, restricting analysis to the T1-5 levels for intercostals and the T6-L1 levels for ab- dominals. The stimulus artifact with 4-pulse trains usually obscured responses from intercostal and abdominal muscles (see Fig. 4A and 4B). To get around this problem, for pedicle track stimulation we tested these levels with a single-pulse stimulus pattern. However, to save time we never tested screws with single-pulse stimulation; hence, we did not have enough data to examine screw stimulation combined with intercostals and/or abdominals as target muscles for predicting screw position.

Inclusion of the intercostals and abdominals in this study was valuable to us because it led to sensitivity and specificity measures of screw position (Fig. 8) that were roughly comparable to or better than those from other studies. ${ }^{55,60}$ Not only did this allow us to corroborate findings from these other studies, but we effectively had a baseline against which we could compare findings from our novel approach. Having now done this and shown that monitoring leg EMG activity is far more reliable for predicting medially malpositioned screws, we see no advantage to continuing to monitor intercostal or abdominal muscle groups going forward and have stopped this practice.

\section{Is There any Benefit to Using Single-Pulse Stimulation?}

We found that single-pulse stimulation was very effective for differentiating between evoked responses in legs mediated by upper motor neuron axons in the spinal cord and those from direct stimulation of lower motor neuron axons. As a target muscle group, the quadriceps was especially useful for helping make this distinction, as this muscle group was far more likely to respond to single-pulse stimulation, but only when testing was at or caudal to the T-11 level. Pulse-train stimulation led to stimulus thresholds for quadriceps-based responses that were indistinguishable from those of single-pulse stimulation, however, so the single-pulse stimulation was not in and of itself any better for testing these levels compared with pulse-train stimulation.

While of interest from a scientific standpoint, now that we have demonstrated this relationship we see little practical value to differentiating between nerve rootmediated and spinal cord-mediated evoked responses going forward. That is, knowing which fibers mediated this response did not change any actions we took when thresholds were particularly low and suggestive of a medial defect (these actions are detailed in the companion report ${ }^{7}$ ). Where single-pulse stimulation was helpful for us was in the interpretation of findings from the rare patients ( 2 of 75 ) in whom responses from leg muscles were evoked by stimulation of spine levels rostral to T-11 with single-pulse inputs. Both of these patients showed enhanced deep-tendon and withdrawal reflexes, consistent with spinal cord hyperexcitability. In both patients, the thresholds of multiple lower limb muscles to multi-pulse pedicle track stimulation with the ball-tipped probe were between 10 and $15 \mathrm{~mA}$ (that is within our alarm range for detecting medial defects $\geq 2 \mathrm{~mm}$ ), yet the screw threads of all these (relatively) low-threshold sites were well-removed from the medial wall of their respective pedicles.

At the risk of over-interpreting the results of such a small sample, our finding of responses to repeated single- 


\section{B. Calancie et al.}

pulse stimulation of more rostral-lying spine levels-in the absence of medially malpositioned screws-in these 2 hyperreflexive patients suggests that the low thresholds to multi-pulse stimulation that we initially encountered could be disregarded. That is, for these particular patients we could probably adjust our alarm thresholds from the 10 and $15 \mathrm{~mA}$ values described earlier, to a more aggressive range (for example, 8 and $13 \mathrm{~mA}$ ) without fear of missing a real breach or of generating an excessive number of false alarms. Given this benefit of single-pulse testing for helping to recognize patients with a hyperexcitable spinal cord, and since testing with single-pulse stimulation adds no more than a few seconds to the time needed to test an uneventful pedicle track, we will continue to do so for neuromonitoring of thoracic pedicle screws.

\section{Can our Method Predict Foraminal Defects?}

The answer appears to be "sometimes," but it is not immediately obvious when a breach is in the foramen versus the spinal canal itself. Both types of breaches led to much lower thresholds than for pedicle tracks (or screw placements) that did not breach the pedicle's wall. In fact, each of the 8 cases of foraminal breaches described (see Fig. 9) led to a false positive in our ROC analysis shown in Fig. 8; without these data points, our accuracy for detecting medial breaches would have been better still (that is, fewer false positives for cutoff values under $10 \mathrm{~mA}$ ). One clue that a defect might be foraminal is that in 7 of the 8 cases seen, there was strong bilateral recruitment at low thresholds. It is not clear to us why this should be the case. Note that strong bilateral responses to foraminal stimulation argues against absolute distance from the spinal cord as being the primary mediator of the probability of a response to pedicle screw testing. ${ }^{41}$

Could our protocol be revised to improve upon our ability to differentiate between a medial malpositioning of a screw into the canal versus into a foramen? One way would be to place a probe along the pedicle track and take a lateral fluoroscopic image of that spine region. To save time, this could be done with any pedicle track that tested with a suspiciously low threshold and bilateral recruitment before the screw was placed in that suspect track. Whereas intraoperative fluoroscopy is widely considered to be poor for recognizing medial breaches in the pedicle wall, breaches in the superior/inferior orientation are immediately evident with a lateral scan.

\section{What Nerves Are Being Activated with Stimulation?}

Results of our testing strategy, similar in many aspects other than the point of stimulation to those for transcranial MEP monitoring, suggest that it is corticospinal tract fibers that are mediating the lower limb evoked responses to pedicle track- and screw-based stimulation, at least at levels rostral to T-11. For example, notice how there is only a slight fall-off in magnitudes of the responses evoked from leg muscles going from a 4-pulse to a 3-pulse train (Fig. 10B and C), a much more pronounced drop in response going from a 3-pulse to a 2-pulse train (Fig. 10C and D), and a complete loss of responses to single-pulse stimulation (Fig. 10E). This shows the importance of tem- poral summation of synaptic inputs to a lower motor neuron's soma to cause it to reach firing threshold, behavior that is virtually identical to that seen for transcranial MEP testing (for an example, see Fig. 2 from Calancie et al. ${ }^{8}$ ). Another clue that it is corticospinal tract fibers mediating these responses is the strong preponderance for recruitment of the tibialis anterior and (especially) the abductor hallucis muscles compared with the quadriceps, for stimulation rostral to T-11. This tendency is also seen with transcranial MEP testing, both in the operating room using electrical stimulation ${ }^{8}$ and in the laboratory setting using magnetic stimulation in awake patients. ${ }^{5}$

Could the results of 4-pulse stimulation described herein be mediated by back-stimulation of Type Ia afferent axons ascending within the dorsal columns? In other words, could the responses we describe be caused by Hreflexes? The answer is "no," for two reasons. First, Hreflexes are not uniformly distributed across all muscle groups of the lower limbs. In fact unless the patient has a history of chronic spinal cord injury, it is rare to see $\mathrm{H}$ reflexes from either the tibialis anterior muscle (for common peroneal stimulation) or abductor hallucis muscle (for posterior tibial stimulation), ${ }^{34}$ yet these two muscles were the most likely to be activated by our stimulus paradigm. Secondly, H-reflexes are subject to low-frequency depression, whereby with repeated stimulation the amplitude of later H-reflexes is attenuated compared with the first H-reflex by an amount dependent upon the rate of nerve stimulation. ${ }^{12,14,30}$ For the rates of stimulation we used in this study $(3 \mathrm{~Hz})$, low-frequency depression would be expected to cause a drop in H-reflex amplitude to approximately $60 \%$ of the first reflex in a test series. ${ }^{6}$ We saw no attenuation whatsoever of evoked responses to repeated pedicle track- or screw-based stimulation at $3 \mathrm{~Hz}$, provided that the stimulating probe was held in the same position and the stimulus intensity was kept constant.

\section{Conclusions}

In this blinded and randomized study, we developed and validated a novel neuromonitoring method for predicting medial malpositioning of thoracic pedicle screws during spine surgery. Features essential to this approach include stimulation within the pedicle track (before the screw is placed), use of a 4-pulse stimulus train to optimize recruitment of lower motor neurons, and monitoring EMG activity from lower limb muscles rather than locally innervated muscles such as intercostals and abdominals. Using these inputs and outputs, a 10-mA alarm threshold had a probability of 0.88 of detecting a clinically relevant $(\geq 2 \mathrm{~mm}$ ) medial breach by an implanted screw, and this probability increased to 1.0 with a $15-\mathrm{mA}$ alarm cutoff. That is, a $15-\mathrm{mA}$ alarm predicted $100 \%$ of the 32 screws implanted in this study with a clinically relevant medial breach. In light of these results, the rates of false positives associated with these $10 \mathrm{~mA}$ and $15 \mathrm{~mA}$ alarm cutoffs (10\% and $26 \%$, respectively) represent a considerable improvement over existing approaches. This study underscores findings from our earlier study that screw stimulation alone is inadequate for monitoring thoracic pedicle screw placement and will more than likely contribute to 


\section{Pulse-train stimulation and thoracic pedicle screws: Part 1}

a false sense of security in the spine surgeon, because of its low sensitivity to screw malpositioning. ${ }^{19}$ Finally, traditional neuromonitoring testing of SSEPs and transcranial MEPs failed to detect any of these 32 malpositioned screws, confirming their inadequacy for detecting medial malpositioning of pedicle screws in the thoracic spine in the absence of acute cord trauma or ischemia.

\section{Acknowledgments}

We thank Evan Belanger, Margaret Fischer, and Catherine Murtagh-Schaffer for help with obtaining patient consent; John Smale of Digitimer Ltd. for providing us with a device to capture the voltage-equivalent magnitude of constant-current stimulation pulses delivered to patients; Chuck Hughes and SPS Medical (Rush, New York) for performing sterilization validation of the ball-tipped probe we used in roughly half of our cases; Douglas Robertson for helpful discussions of ROC analysis; and the operating room staff of Crouse Hospital and Upstate University Hospital (Syracuse, New York) for squeezing our outsized instrumentation rack into their already crowded domains.

\section{Disclosure}

This study was supported by a grant from the National Institutes of Health to B. Calancie (NS R01 NS063055). Digitimer Limited (Welwyn Garden City, UK) designed and provided the authors with a current:voltage adapter for recording voltage pulses calibrated to the intensity of current pulses being delivered. Dr. Moquin reports a consultant relationship with $\mathrm{K} 2 \mathrm{M}$.

Author contributions to the study and manuscript preparation include the following. Conception and design: Calancie, Moquin. Acquisition of data: Calancie, Donohue, Harris, Canute, Moquin. Analysis and interpretation of data: Calancie, Donohue, Singla, Wilcoxen. Drafting the article: Calancie. Critically revising the article: all authors. Reviewed submitted version of manuscript: all authors. Approved the final version of the manuscript on behalf of all authors: Calancie. Statistical analysis: Calancie, Donohue. Administrative/ technical/material support: Calancie. Study supervision: Calancie.

\section{References}

1. Aebi M, Etter C, Kehl T, Thalgott J: Stabilization of the lower thoracic and lumbar spine with the internal spinal skeletal fixation system. Indications, techniques, and first results of treatment. Spine (Phila Pa 1976) 12:544-551, 1987

2. Albayram S, Ulu MO, Hanimoglu H, Kaynar MY, Hanci M: Intracranial hypotension following scoliosis surgery: dural penetration of a thoracic pedicle screw. Eur Spine J 17 (Suppl 2):S347-S350, 2008

3. Belmont PJ Jr, Klemme WR, Robinson M, Polly DW Jr: Accuracy of thoracic pedicle screws in patients with and without coronal plane spinal deformities. Spine (Phila Pa 1976) 27: $1558-1566,2002$

4. Bharucha NJ, Lonner BS, Auerbach JD, Kean KE, Trobisch PD: Low-density versus high-density thoracic pedicle screw constructs in adolescent idiopathic scoliosis: do more screws lead to a better outcome? Spine J 13:375-381, 2013

5. Calancie B, Alexeeva N, Broton JG, Suys S, Hall A, Klose KJ: Distribution and latency of muscle responses to transcranial magnetic stimulation of motor cortex after spinal cord injury in humans. J Neurotrauma 16:49-67, 1999

6. Calancie B, Broton JG, Klose KJ, Traad M, Difini J, Ayyar DR: Evidence that alterations in presynaptic inhibition contribute to segmental hypo- and hyperexcitability after spinal cord injury in man. Electroencephalogr Clin Neurophysiol 89:177-186, 1993
7. Calancie B, Donohue ML, Moquin RR: Neuromonitoring with pulse-train stimulation for implantation of thoracic pedicle screws: a blinded and randomized clinical study. Part 2. The role of feedback. Clinical article. J Neurosurg Spine [epub ahead of print April 1, 2014.DOI: 10.3171/2014.2.SPINE13649]

8. Calancie B, Harris W, Broton JG, Alexeeva N, Green BA: "Threshold-level" multipulse transcranial electrical stimulation of motor cortex for intraoperative monitoring of spinal motor tracts: description of method and comparison to somatosensory evoked potential monitoring. J Neurosurg 88: 457-470, 1998

9. Calancie B, Lebwohl N, Madsen P, Klose KJ: Intraoperative evoked EMG monitoring in an animal model. A new technique for evaluating pedicle screw placement. Spine (Phila Pa 1976) 17:1229-1235, 1992

10. Calancie B, Madsen P, Lebwohl N: Stimulus-evoked EMG monitoring during transpedicular lumbosacral spine instrumentation. Initial clinical results. Spine (Phila Pa 1976) 19: 2780-2786, 1994

11. Clements DH, Morledge DE, Martin WH, Betz RR: Evoked and spontaneous electromyography to evaluate lumbosacral pedicle screw placement. Spine (Phila Pa 1976) 21:600-604, 1996

12. Cook WA Jr: Effects of low frequency stimulation on the monosynaptic reflex (H reflex) in man. Neurology 18:47-51, 1968

13. Cuartas E, Rasouli A, O'Brien M, Shufflebarger HL: Use of all-pedicle-screw constructs in the treatment of adolescent idiopathic scoliosis. J Am Acad Orthop Surg 17:550-561, 2009

14. Curtis DR, Eccles JC: Synaptic action during and after repetitive stimulation. J Physiol 150:374-398, 1960

15. Danesh-Clough T, Taylor P, Hodgson B, Walton M: The use of evoked EMG in detecting misplaced thoracolumbar pedicle screws. Spine (Phila Pa 1976) 26:1313-1316, 2001

16. de Blas G, Burgos J, Regidor I, Barrios C, Solá R, GarcíaUrquiza $S$, et al: Recording diffusion responses from contralateral intercostal muscles after stimulus-triggered electromyography: refining a tool for the assessment of thoracic pedicle screw placement in an experimental porcine model. Spine (Phila Pa 1976) 34:E391-E396, 2009

17. Diab M, Smith AR, Kuklo TR: Neural complications in the surgical treatment of adolescent idiopathic scoliosis. Spine (Phila Pa 1976) 32:2759-2763, 2007

18. Donohue ML, Murtagh-Schaffer C, Basta J, Moquin RR, Bashir A, Calancie B: Pulse-train stimulation for detecting medial malpositioning of thoracic pedicle screws. Spine (Phila Pa 1976) 33:E378-E385, 2008

19. Donohue ML, Swaminathan V, Gilbert JL, Fox CW, Smale J, Moquin RR, et al: Intraoperative neuromonitoring: can the results of direct stimulation of titanium-alloy pedicle screws in the thoracic spine be trusted? J Clin Neurophysiol 29:502508, 2012

20. Duffy MF, Phillips JH, Knapp DR, Herrera-Soto JA: Usefulness of electromyography compared to computed tomography scans in pedicle screw placement. Spine (Phila Pa 1976) 35: E43-E48, 2010

21. Ferrick MR, Kowalski JM, Simmons ED Jr: Reliability of roentgenogram evaluation of pedicle screw position. Spine (Phila Pa 1976) 22:1249-1253, 1997

22. Finkelstein JA: Can triggered electromyograph thresholds predict safe thoracic pedicle screw placement. Spine (Phila Pa 1976) 28:960, 2003 (Letter)

23. Gang C, Haibo L, Fancai L, Weishan C, Qixin C: Learning curve of thoracic pedicle screw placement using the free-hand technique in scoliosis: how many screws needed for an apprentice? Eur Spine J 21:1151-1156, 2012

24. Gertzbein SD, Robbins SE: Accuracy of pedicular screw placement in vivo. Spine (Phila Pa 1976) 15:11-14, 1990

25. Glassman SD, Dimar JR, Puno RM, Johnson JR, Shields CB, Linden RD: A prospective analysis of intraoperative electro- 
myographic monitoring of pedicle screw placement with computed tomographic scan confirmation. Spine (Phila Pa 1976) 20:1375-1379, 1995

26. Grauer JN, Vaccaro AR, Brusovanik G, Girardi FP, Silveri $\mathrm{CP}$, Cammisa FP, et al: Evaluation of a novel pedicle probe for the placement of thoracic and lumbosacral pedicle screws. J Spinal Disord Tech 17:492-497, 2004

27. Hart RA, Hansen BL, Shea M, Hsu F, Anderson GJ: Pedicle screw placement in the thoracic spine: a comparison of imageguided and manual techniques in cadavers. Spine (Phila Pa 1976) 30:E326-E331, 2005

28. Hicks JM, Singla A, Shen FH, Arlet V: Complications of pedicle screw fixation in scoliosis surgery: a systematic review. Spine (Phila Pa 1976) 35:E465-E470, 2010

29. Hwang CJ, Lee CK, Chang BS, Kim MS, Yeom JS, Choi JM: Minimum 5-year follow-up results of skipped pedicle screw fixation for flexible idiopathic scoliosis. Clinical article. J Neurosurg Spine 15:146-150, 2011

30. Ishikawa K, Ott K, Porter RW, Stuart D: Low frequency depression of the $\mathrm{H}$ wave in normal and spinal man. Exp Neurol 15:140-156, 1966

31. Isley MR, Pearlman RC, Wadsworth JS: Recent advances in intraoperative neuromonitoring of spinal cord function: pedicle screw stimulation techniques. Am J Electroneurodiagnostic Technol 37:93-126, 1997

32. Kepler CK, Vacaro AR: Editorial. Skipped pedicle screws. J Neurosurg Spine 15:144-145, 2011 (Erratum in J Neurosurg Spine 15:692, 2011)

33. Kim YJ, Lenke LG, Bridwell KH, Cho YS, Riew KD: Free hand pedicle screw placement in the thoracic spine: is it safe? Spine (Phila Pa 1976) 29:333-342, 2004

34. Kimura J: Clinical electrophysiology of peripheral nervous system axons, in Waxman SG, Kocsis JD, Stys PK (eds): The Axon: Structure, Function and Pathophysiology. New York: Oxford University Press, 1995, pp 590-628

35. Kosmopoulos V, Schizas C: Pedicle screw placement accuracy: a meta-analysis. Spine (Phila Pa 1976) 32:E111-E120, 2007

36. Larson AN, Santos ER, Polly DW Jr, Ledonio CG, Sembrano $\mathrm{JN}$, Mielke CH, et al: Pediatric pedicle screw placement using intraoperative computed tomography and 3-dimensional image-guided navigation. Spine (Phila Pa 1976) 37:E188E194, 2012

37. Lehman RA Jr, Lenke LG, Keeler KA, Kim YJ, Cheh G: Computed tomography evaluation of pedicle screws placed in the pediatric deformed spine over an 8-year period. Spine (Phila Pa 1976) 32:2679-2684, 2007

38. Lewis SJ, Lenke LG, Raynor B, Long J, Bridwell KH, Padberg A: Triggered electromyographic threshold for accuracy of thoracic pedicle screw placement in a porcine model. Spine (Phila Pa 1976) 26:2485-2490, 2001

39. Mac-Thiong JM, Parent S, Poitras B, Joncas J, Hubert L: Neurological outcome and management of pedicle screws misplaced totally within the spinal canal. Spine (Phila Pa 1976) 38:229-237, 2013

40. Maguire J, Wallace S, Madiga R, Leppanen R, Draper V: Evaluation of intrapedicular screw position using intraoperative evoked electromyography. Spine (Phila Pa 1976) 20:10681074, 1995

41. Montes E, De Blas G, Regidor I, Barrios C, Burgos J, Hevia E, et al: Electromyographic thresholds after thoracic screw stimulation depend on the distance of the screw from the spinal cord and not on pedicle cortex integrity. Spine J 12:127-132, 2012

42. Nuwer MR, Dawson EG, Carlson LG, Kanim LEA, Sherman JE: Somatosensory evoked potential spinal cord monitoring reduces neurologic deficits after scoliosis surgery: results of a large multicenter survey. Electroencephalogr Clin Neurophysiol 96:6-11, 1995

43. Papin P, Arlet V, Marchesi D, Rosenblatt B, Aebi M: Unusual presentation of spinal cord compression related to misplaced pedicle screws in thoracic scoliosis. Eur Spine J 8:156-159, 1999

44. Parker SL, McGirt MJ, Farber SH, Amin AG, Rick AM, Suk I, et al: Accuracy of free-hand pedicle screws in the thoracic and lumbar spine: analysis of 6816 consecutive screws. Neurosurgery 68:170-178, 2011

45. Pechstein U, Cedzich C, Nadstawek J, Schramm J: Transcranial high-frequency repetitive electrical stimulation for recording myogenic motor evoked potentials with the patient under general anesthesia. Neurosurgery 39:335-344, 1996

46. Polly DW Jr, Potter BK, Kuklo T, Young S, Johnson C, Klemme WR: Volumetric spinal canal intrusion: a comparison between thoracic pedicle screws and thoracic hooks. Spine (Phila Pa 1976) 29:63-69, 2004

47. Qiu Y, Wang WJ, Wang B, Zhu F, Zhu ZZ, Ng BK, et al: Accuracy of thoracic vertebral screw insertion in adolescent idiopathic scoliosis: a comparison between thoracoscopic and mini-open thoracotomy approaches. Spine (Phila Pa 1976) 33:2637-2642, 2008

48. Quan GM, Gibson MJ: Correction of main thoracic adolescent idiopathic scoliosis using pedicle screw instrumentation: does higher implant density improve correction? Spine (Phila Pa 1976) 35:562-567, 2010

49. Rampersaud YR, Lee KS: Fluoroscopic computer-assisted pedicle screw placement through a mature fusion mass: an assessment of 24 consecutive cases with independent analysis of computed tomography and clinical data. Spine (Phila Pa 1976) 32:217-222, 2007

50. Rampersaud YR, Pik JH, Salonen D, Farooq S: Clinical accuracy of fluoroscopic computer-assisted pedicle screw fixation: a CT analysis. Spine (Phila Pa 1976) 30:E183-E190, 2005

51. Rao G, Brodke DS, Rondina M, Bacchus K, Dailey AT: Inter- and intraobserver reliability of computed tomography in assessment of thoracic pedicle screw placement. Spine (Phila Pa 1976) 28:2527-2530, 2003

52. Rao G, Brodke DS, Rondina M, Dailey AT: Comparison of computerized tomography and direct visualization in thoracic pedicle screw placement. J Neurosurg 97 (2 Suppl):223-226, 2002

53. Raynor BL, Lenke LG, Kim Y, Hanson DS, Wilson-Holden TJ, Bridwell KH, et al: Can triggered electromyograph thresholds predict safe thoracic pedicle screw placement? Spine (Phila Pa 1976) 27:2030-2035, 2002

54. Regidor I, de Blas G, Barrios C, Burgos J, Montes E, GarcíaUrquiza S, et al: Recording triggered EMG thresholds from axillary chest wall electrodes: a new refined technique for accurate upper thoracic (T2-T6) pedicle screw placement. Eur Spine J 20:1620-1625, 2011

55. Reidy DP, Houlden D, Nolan PC, Kim M, Finkelstein JA: Evaluation of electromyographic monitoring during insertion of thoracic pedicle screws. J Bone Joint Surg Br 83:10091014,2001

56. Rodriguez-Olaverri JC, Zimick NC, Merola A, De Blas G, Burgos J, Piza-Vallespir G, et al: Using triggered electromyographic threshold in the intercostal muscles to evaluate the accuracy of upper thoracic pedicle screw placement (T3-T6). Spine (Phila Pa 1976) 33:E194-E197, 2008

57. Rose RD, Welch WC, Balzer JR, Jacobs GB: Persistently electrified pedicle stimulation instruments in spinal instrumentation. Technique and protocol development. Spine (Phila Pa 1976) 22:334-343, 1997

58. Roy-Camille R, Saillant G, Mazel C: Internal fixation of the lumbar spine with pedicle screw plating. Clin Orthop Relat Res (203):7-17, 1986

59. Samdani AF, Ranade A, Sciubba DM, Cahill PJ, Antonacci MD, Clements DH, et al: Accuracy of free-hand placement of thoracic pedicle screws in adolescent idiopathic scoliosis: how much of a difference does surgeon experience make? Eur Spine J 19:91-95, 2010

60. Samdani AF, Tantorski M, Cahill PJ, Ranade A, Koch S, 


\section{Pulse-train stimulation and thoracic pedicle screws: Part 1}

Clements DH, et al: Triggered electromyography for placement of thoracic pedicle screws: is it reliable? Eur Spine J 20:869-874, 2011

61. Santos ER, Ledonio CG, Castro CA, Truong WH, Sembrano JN: The accuracy of intraoperative $\mathrm{O}$-arm images for the assessment of pedicle screw postion. Spine (Phila Pa 1976) 37: E119-E125, 2012

62. Sarlak AY, Tosun B, Atmaca H, Sarisoy HT, Buluç L: Evaluation of thoracic pedicle screw placement in adolescent idiopathic scoliosis. Eur Spine J 18:1892-1897, 2009

63. Schwarzenbach O, Berlemann U, Jost B, Visarius H, Arm E, Langlotz F, et al: Accuracy of computer-assisted pedicle screw placement. An in vivo computed tomography analysis. Spine (Phila Pa 1976) 22:452-458, 1997

64. Shi YB, Binette M, Martin WH, Pearson JM, Hart RA: Electrical stimulation for intraoperative evaluation of thoracic pedicle screw placement. Spine (Phila Pa 1976) 28:595-601, 2003

65. Silbermann J, Riese F, Allam Y, Reichert T, Koeppert H, Gutberlet M: Computer tomography assessment of pedicle screw placement in lumbar and sacral spine: comparison between free-hand and O-arm based navigation techniques. Eur Spine J 20:875-881, 2011

66. Suk SI, Lee CK, Min HJ, Cho KH, Oh JH: Comparison of Cotrel-Dubousset pedicle screws and hooks in the treatment of idiopathic scoliosis. Int Orthop 18:341-346, 1994

67. Toleikis JR, Skelly JP, Carlvin AO, Toleikis SC, Bernard TN, Burkus JK, et al: The usefulness of electrical stimulation for assessing pedicle screw placements. J Spinal Disord 13:283289,2000

68. Ughwanogho E, Patel NM, Baldwin KD, Sampson NR, Flynn
JM: Computed tomography-guided navigation of thoracic pedicle screws for adolescent idiopathic scoliosis results in more accurate placement and less screw removal. Spine (Phila Pa 1976) 37:E473-E478, 2012

69. Upendra BN, Meena D, Chowdhury B, Ahmad A, Jayaswal A: Outcome-based classification for assessment of thoracic pedicular screw placement. Spine (Phila Pa 1976) 33:384-390, 2008

70. Watanabe K, Lenke LG, Bridwell KH, Kim YJ, Watanabe K, Kim YW, et al: Comparison of radiographic outcomes for the treatment of scoliotic curves greater than 100 degrees: wires versus hooks versus screws. Spine (Phila Pa 1976) 33:10841092, 2008

71. Weinstein JN, Rydevik BL, Rauschning W: Anatomic and technical considerations of pedicle screw fixation. Clin Orthop Relat Res (284):34-46, 1992

Manuscript submitted July 9, 2013.

Accepted February 10, 2014.

Different aspects of this project have been presented via podium slide-show format at several annual meetings of the American Society for Neurophysiological Monitoring, including Vancouver (2009), Nashville (2010), Salt Lake City (2012), and Boston (2013).

Please include this information when citing this paper: published online April 1, 2014; DOI: 10.3171/2014.2.SPINE13648.

Address correspondence to: Blair Calancie, Ph.D., 750 E. Adams St., IHP \#1213, Syracuse, NY 13210. email: calancib@upstate.edu. 